ARTICLE

\title{
Foreign body responses in mouse central nervous system mimic natural wound responses and alter biomaterial functions
}

Timothy M. O'Shea (1) ${ }^{1}$, Alexander L. Wollenberg ${ }^{2}$, Jae H. Kim¹, Yan Ao ${ }^{1}$, Timothy J. Deming (i) ${ }^{2,3}$ \& Michael V. Sofroniew (1) ${ }^{1 \times}$

Biomaterials hold promise for therapeutic applications in the central nervous system (CNS). Little is known about molecular factors that determine CNS foreign body responses (FBRs) in vivo, or about how such responses influence biomaterial function. Here, we probed these factors in mice using a platform of injectable hydrogels readily modified to present interfaces with different physiochemical properties to host cells. We found that biomaterial FBRs mimic specialized multicellular CNS wound responses not present in peripheral tissues, which serve to isolate damaged neural tissue and restore barrier functions. We show that the nature and intensity of CNS FBRs are determined by definable properties that significantly influence hydrogel functions, including resorption and molecular delivery when injected into healthy brain or stroke injuries. Cationic interfaces elicit stromal cell infiltration, peripherally derived inflammation, neural damage and amyloid production. Nonionic and anionic formulations show minimal levels of these responses, which contributes to superior bioactive molecular delivery. Our results identify specific molecular mechanisms that drive FBRs in the CNS and have important implications for developing effective biomaterials for CNS applications.

\footnotetext{
${ }^{1}$ Department of Neurobiology, David Geffen School of Medicine, University of California, Los Angeles, CA 90095-1763, USA. ${ }^{2}$ Department of Chemistry and Biochemistry, University of California Los Angeles, Los Angeles, CA 90095-1600, USA. ${ }^{3}$ Department of Bioengineering, University of California Los Angeles, Los Angeles, CA 90095-1600, USA. ${ }^{凶}$ email: sofroniew@mednet.ucla.edu
} 
B iomaterials are under widespread investigation for experimental and therapeutic applications in the central nervous system $(\mathrm{CNS})^{1}$. Biomaterials with specialized properties have been incorporated in implantable neuroprostheses that are used clinically for recording neuronal activity and stimulating neural circuits in the $\mathrm{CNS}^{2,3}$. In addition, injectable biomaterial hydrogels are used extensively as experimental tools to provide local delivery of growth factors, for example, to attract injured and regenerating axons to grow across CNS lesions ${ }^{4,5}$ as well as to afford molecular and physical support to co-suspended neural progenitor cells to improve survival and modulate differentiation upon grafting into the $\mathrm{CNS}^{6-8}$.

Although various classes of biomaterials may be used for applications in the CNS, synthetic, or naturally derived polymers are the predominate choice for directly interfacing with host CNS tissue and cells ${ }^{9,10}$. For neuroprostheses, diverse classes of polymers are used as the outer substrates or coatings for metal electrodes intended to improve device insertion and long-term performance in vivo ${ }^{10,11}$. In addition, new devices based on electrically conducting polymers are also being developed ${ }^{12}$. For hydrogels, considerable progress has been made in synthesizing new polymers with tunable physiochemical properties to achieve spatial and temporal control of molecular release or provide unique support to co-suspended cells ${ }^{13-16}$.

Despite innovations in the many engineering and design aspects of biomaterials that are used for CNS applications, little is known about factors that determine the CNS foreign body response (FBR) in vivo to these materials, or how such responses influence function. Assessments of cytotoxicity and biocompatibility of biomaterial interfaces with host cells, or biomaterial functions such as molecular release kinetics are often evaluated primarily in vitro or through subcutaneous implantation in vivo ${ }^{17,18}$. However, in vitro observations and the FBR associated with subcutaneously implanted biomaterials need not predict in vivo performance in the CNS, where there is a highly specialized and unique multicellular wound response that serves to isolate damaged tissue and restore barrier functions.

Substantial advances have been made in understanding the CNS wound response, which can inform the study of CNS FBRs. The CNS wound response is a biologically conserved process whereby perturbations of CNS tissue lead to dynamic multicellular interactions that efficiently isolate regions perceived as damaged, infected, or diseased to protect adjacent viable neural tissue and permit recruited inflammation to resolve potentially noxious elements ${ }^{5,19-21}$. This multicellular CNS wound response generates tissue lesions characterized by distinct non-neural and neural cellular compartments in which non-neural lesion cores with stromal and inflammatory cells are segregated from adjacent spared and viable neural tissue by an astroglial border 22 . The cellular responses to materials perceived as foreign are likely to be related to this multicellular natural wound response ${ }^{23}$, but the study of CNS FBRs to biomaterials in vivo has not kept pace with recent advances made in the cell biology of CNS injury. There is a need to better understand: (i) key cellular interactions of CNS FBRs to biomaterials, (ii) biomaterial properties that influence the severity of CNS FBRs, and (iii) the extent to which CNS FBRs influence biomaterial function in vivo. Here, we evaluated these parameters by comparing multiple synthetic and naturally derived hydrogel-based biomaterials.

As a platform to determine the effects of specific molecular features on biomaterial-evoked FBRs, we used synthetic, diblock copolypeptide hydrogels (DCH), which can be readily modified to present interfaces with different representative physiochemical properties to host cells whilst retaining consistent polymer chain lengths and mechanical properties $8,24,25$. These shear-thinning, physical hydrogels can be administered to focal CNS regions in a minimally invasive manner by infusion through narrow cannulae ensuring that minimal tissue damage is induced by the implantation of the biomaterial that could otherwise confound the CNS FBR evaluation of the host-biomaterial interface ${ }^{24-26}$. Moreover, because these hydrogels can be prepared to exhibit the same mechanical stiffness as CNS tissue (ca. 100-400 Pa ${ }^{25}$, they can be fixed and processed in situ and retain their intimate contact with immediately adjacent host cells so that directly contiguous biomaterial-host interfaces can be examined and quantified in detail. This type of analysis is not possible with rigid, mechanically stiff or hydrophobic materials and coated electrodes that must be removed before tissue sectioning, because this removal invariably also disrupts the immediate material-cellular interfaces, which cannot then be evaluated.

We benchmarked our findings using $\mathrm{DCH}$ that present physiochemically defined interfaces against various commonly used, commercially available and previously CNS-tested hydrogel formulations. We compared biomaterial FBRs with naturally evoked CNS wound responses modeled using chemically induced ischemic strokes that were equivalent in size to the hydrogel depots. We tested the effects of CNS FBRs on hydrogel functions when hydrogels were either injected into healthy uninjured brain or into subacute stroke lesions. We show that CNS FBRs to biomaterials mimic conserved elements of CNS wound healing and exists on a definable severity spectrum characterized by the presence or absence of specific different types of non-neural cells. We show that the nature and intensity of CNS FBRs are determined by definable material properties and elicit quantifiable differences in hydrogel functions such as resorption and molecular delivery in both healthy and stroke injured brains. Lastly, we found that severe FBRs provoked by certain hydrogels injected into CNS strokes can disrupt naturally occurring reparative wound responses.

\section{Results}

Hydrogel-evoked FBRs vary and mimic CNS wound responses. We first compared cellular profiles of mild or severe CNS wound responses with FBRs of two structurally similar, synthetic, diblock copolypeptide hydrogels $(\mathrm{DCH})$ that present either strongly cationic $\left(\mathrm{DCH}_{\mathrm{K}}\right)$ or nonionic $\left(\mathrm{DCH}_{\mathrm{MO}}\right)$ interfaces to host cells (Fig. 1a). Lysine-based $\mathrm{DCH}_{\mathrm{K}}$ and methionine sulfoxide based $\mathrm{DCH}_{\mathrm{MO}}$ are both well tolerated in vivo ${ }^{8,25}$, but exhibit noticeably different FBRs. For comparison, mild or severe CNS wound responses were induced by injection of innocuous phosphate buffered saline (PBS), or N5-(1-iminoethyl)-l-ornithine (L-NIO) solution that creates a small focal ischemic stroke ${ }^{27}$. PBS, $\mathrm{DCH}_{\mathrm{MO}}, \mathrm{DCH}_{\mathrm{K}}$, or L-NIO were injected into caudate putamen (CP) of mouse forebrain (Fig. 1b). The CP site is easily accessible, allows for consistent and reproducible hydrogel injections that are well tolerated by the mice, and is composed of neural tissue with neuronal cell bodies, myelinated axon bundles and a diversity of neuroglial making it an advantageous location for standardized CNS FBR assessments ${ }^{25}$. Hydrogel FBRs and wound responses were characterized with immunohistochemistry (IHC) for CD13 to identify non-neural cells including stromal and peripheral myeloid lineage cells recruited as part of the sterile inflammatory response to tissue damage ${ }^{28}$. CD13 positively identifies the full temporal range of non-neural tissue remodeling from acute inflammation through to chronic fibrotic lesion formation. In the healthy uninjured mouse brain, CD13 is expressed by pericytes and perivascular fibroblasts along cerebrovasculature and meningeal fibroblasts ${ }^{29}$ (Supplementary Fig. 1a-d). CD13 is not expressed by neuroglia or neurons. Staining for glial fibrillary acidic protein (GFAP) identified reactive and border-forming 
a

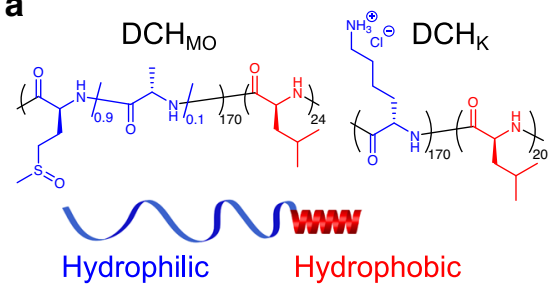

b

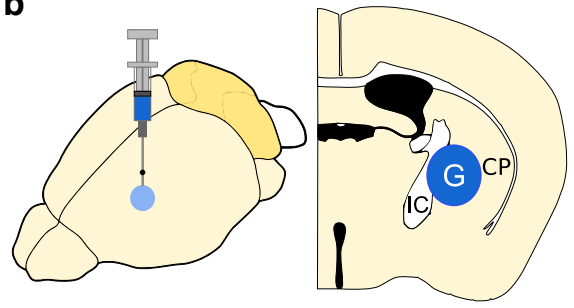

C

1 Week
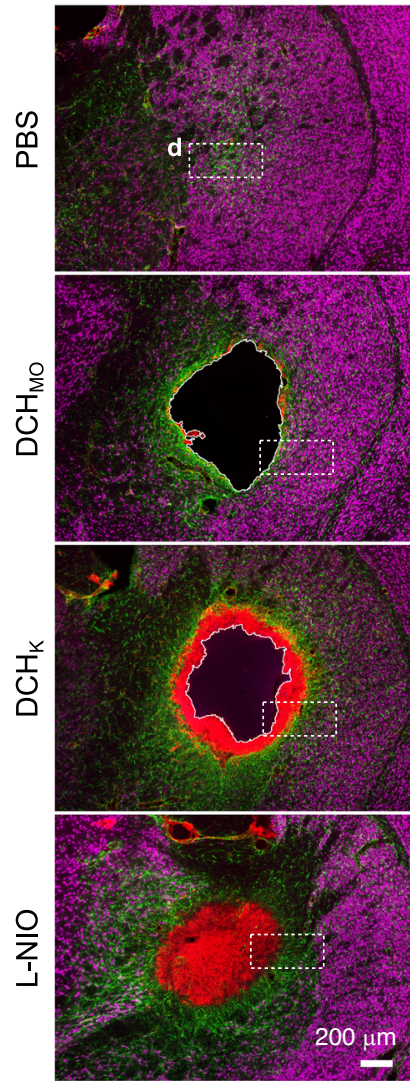

e

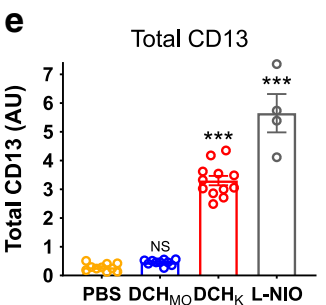

d
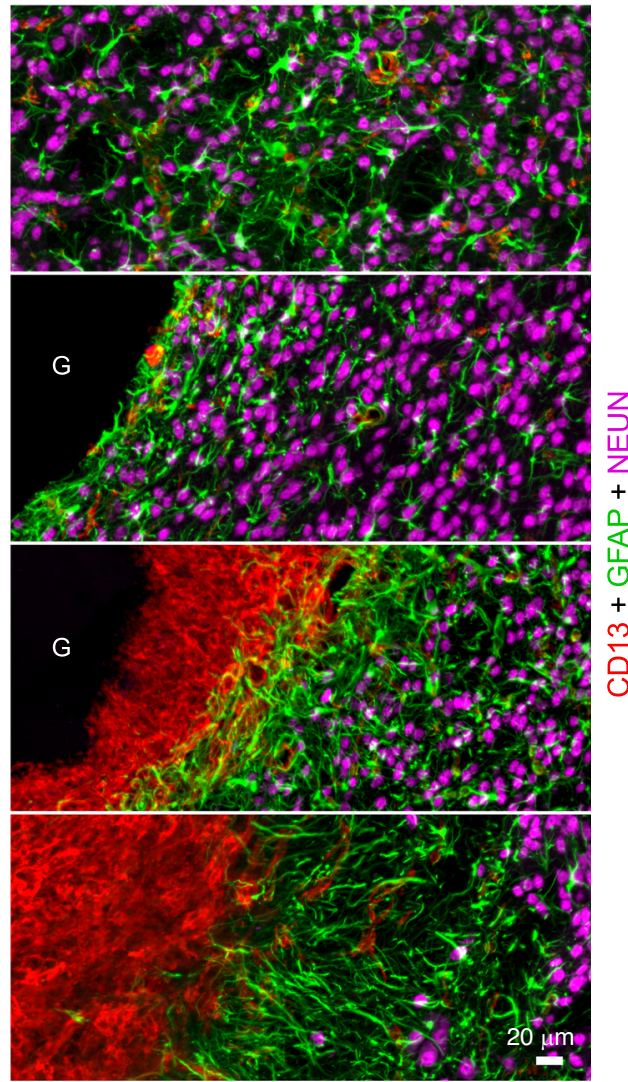

g

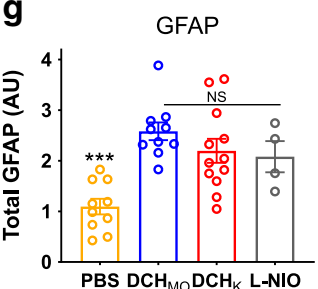

Fig. 1 Hydrogel-evoked FBRs vary and exhibit cellular features of CNS wound response. a Schematic and chemical structures of synthetic hydrogels used as tools to study CNS FBR. $\mathbf{b}$ Experimental model of in vivo injections into caudate putamen (CP) of mouse forebrain. $\mathbf{c}$, $\mathbf{d}$ Survey and detail images of stromal and inflammatory cells (CD13), astrocytes (GFAP), and neurons (NeuN) at 1 week after injections of PBS, hydrogels, or L-NIO-induced stroke. e-g Quantification of total immunohistochemical staining. e Total CD13 in CP. not significant (NS), ${ }^{\star \star \star} P<0.0001$ versus PBS injection, one-way ANOVA with Bonferroni. $\mathbf{f}$ Total CD13 in either non-neural or neural tissue compartments. NS or ${ }^{\star \star \star} P<0.0001$ versus PBS injection, two-way ANOVA with Bonferroni. $\mathbf{g}$ Total GFAP in CP. NS or ${ }^{\star \star \star} P<0.0001$ versus $\mathrm{DCH}_{\mathrm{MO}}$, one-way ANOVA with Bonferroni. All graphs are mean \pm s.e.m with individual data points superimposed showing $n=10,10,12$, and 4 mice per group for PBS, $D C H_{M O}, D_{C H}$, and L-NIO, respectively. $A U$ arbitrary units, $G$ hydrogel, IC internal capsule.

astrocytes $^{30}$, P2RY12 identified CNS microglia and NeuN identified viable neurons.

At 1 week after injections, (i) PBS infusions were detectible as small areas of GFAP-positive reactive astrocytes; (ii) nonionic $\mathrm{DCH}_{\mathrm{MO}}$ and cationic $\mathrm{DCH}_{\mathrm{K}}$, exhibited similarly sized deposits; and (iii) L-NIO created sharply demarcated areas of infarcted tissue equivalent in size to hydrogel deposits (Fig. 1c). $\mathrm{DCH}_{\mathrm{MO}}$ and $\mathrm{DCH}_{\mathrm{K}}$ deposits and L-NIO infarcts were all surrounded by similarly appearing borders of GFAP-positive astrocytes that clearly separated neural tissue containing NeuN-positive neurons from non-neural cores with CD13-positive cells and hydrogels (Fig. 1c, d). CD13-positive cells were not elevated at the centers of 
PBS injections or at interfaces between $\mathrm{DCH}_{\mathrm{MO}}$ and host. By contrast, a dense CD13-positive cell capsule, $164 \pm 19 \mu \mathrm{m}$ in thickness, had completely surrounded and infiltrated the margins of $\mathrm{DCH}_{\mathrm{K}}$ deposits, whereas CD13-positive cells had entirely filled L-NIO infarcts (Fig. 1c, d). Similar CD13-positive cell accumulation and non-neural/neural cell compartmentalization was observed 1 week after forebrain stab injury through cerebral cortex (Supplementary Fig. 1e). Quantification showed that total CD13 levels across the different compartments of infusion sites and adjacent neural tissue were similar after $\mathrm{PBS}$ and $\mathrm{DCH}_{\mathrm{MO}}$ and were significantly higher after $\mathrm{DCH}_{\mathrm{K}}$ and L-NIO (Fig. 1e; Supplementary Fig. 2). Notably, the significant increases in CD13 levels after $\mathrm{DCH}_{\mathrm{K}}$ and L-NIO were confined to central nonneural tissue compartments of hydrogel plus infiltrating cells, and there was no significant difference in CD13 levels in surrounding neural tissue (defined as tissue containing neuroglia and neurons) adjacent to PBS, $\mathrm{DCH}_{\mathrm{MO}}, \mathrm{DCH}_{\mathrm{K}}$, or L-NIO (Fig. 1f). Moreover, although GFAP levels were significantly lower adjacent to PBS injections, there was no significant difference in GFAP levels adjacent to $\mathrm{DCH}_{\mathrm{MO}}, \mathrm{DCH}_{\mathrm{K}}$, or L-NIO (Fig. 1g).

These findings show that DCH-based hydrogels presenting precisely defined cationic $\left(\mathrm{DCH}_{\mathrm{K}}\right)$ or nonionic $\left(\mathrm{DCH}_{\mathrm{MO}}\right)$ interfaces to host cells exhibit FBRs whose cellular profiles and compartmentalization mimic those of normal CNS wound responses that are prominent or minimal, respectively, and that the FBR to different hydrogels can vary significantly. These findings also suggested that hydrogel surface chemistry and properties such as charge may influence hydrogel FBR, which we investigated next.

FBRs vary with definable hydrogel properties. We next characterized FBRs to various cationic, anionic, and nonionic hydrogels. We manufactured DCH that presented different polar side chains to interface with host cells but maintained consistent poly (L-leucine) hydrophobic blocks ${ }^{8,24,25}$ (Supplementary Fig. 3a, b). We compared these $\mathrm{DCH}$ with various commercially available formulations commonly used in CNS applications: methylcellulose $(\mathrm{MC})^{31}$, a hyaluronic acid/methylcellulose blend (HAMC) $)^{32}$, and a chitosan/ $\beta$-glycerophosphate (CHIT) system ${ }^{33}$. Hydrogels with comparable mechanical properties (see ref., ${ }^{8,25,34}$ and Supplementary Fig. 3c) were injected into mouse forebrain (Fig. 1b), and cellular FBR profiles were first characterized with IHC for CD13, GFAP, and NeuN (Fig. 2; Supplementary Figs. 2-5).

Qualitative and quantitative examination showed that nonionic $\mathrm{MC}$, like nonionic $\mathrm{DCH}_{\mathrm{MO}}$, exhibited barely detectable levels of CD13-positive cells at interfaces with host tissue (Fig. 2a, c; Supplementary Fig. 4a). Moreover, anionic hydrogels HAMC as well as glutamate (E) inclusive $\mathrm{DCH}_{\mathrm{E}}$ and $\mathrm{DCH}_{\mathrm{MOE} 15}$ also exhibited barely detectable levels of CD13-positive cells at host interfaces (Fig. 2a, c; Supplementary Fig. 4a). However, in striking contrast, cationic hydrogels, $\mathrm{DCH}_{\mathrm{K}}, \mathrm{DCH}_{\mathrm{MM}}, \mathrm{DCH}_{\mathrm{MOK15}}$, $\mathrm{DCH}_{\mathrm{MOK10}}$, and CHIT all exhibited large rims of CD13positive cells infiltrating into deposits around their entire host interface and had significantly higher CD13 levels in central nonneural compartments, which did not differ in magnitude across different cationic hydrogels (Fig. 2b, c; Supplementary Fig. 4b). To directly probe the relationship between cationic charge and FBR, we incorporated variable amounts of lysine (K) into nonionic $\mathrm{DCH}_{\mathrm{MO}}$ as a statistical copolymer ${ }^{8}$ (Supplementary Fig. $3 \mathrm{~b}$ ). $\mathrm{DCH}_{\mathrm{MOK} 15}$ and $\mathrm{DCH}_{\mathrm{MOK} 10}$ both exhibited outer rims of infiltrating CD13 cells similar to $\mathrm{DCH}_{\mathrm{K}}$, but with more cells infiltrating into the deposit center, suggesting that small amounts of dispersed cationic charge attracted CD13 cells, whereas dense charge in $\mathrm{DCH}_{\mathrm{K}}$ prevented these same cells from distributing throughout the bulk of the material. In addition, we generated cationic, methyl-sulfonium-based $\mathrm{DCH}_{\mathrm{MM}}$ (Supplementary Fig. $3 \mathrm{~b})^{8}$, which also exhibited a rim of infiltrating CD13 cells similar to $\mathrm{DCH}_{\mathrm{K}}$, but in addition exhibited many DAPI-positive but CD13-negative cells that formed a distinct and separated layer of cells that directly interfaced with the hydrogel deposit surface (Fig. 2b). Similar CD13-negative cells at the material interface were not obviously present in other $\mathrm{DCH}$, but were present within CHIT deposits (Fig. 2b), suggesting a distinct cellular infiltrate requiring further characterization as conducted below.

These findings show that hydrogel FBRs vary with definable hydrogel properties and implicate cationic charge presented at material interfaces with host tissue as a major factor determining FBR severity. At interfaces with host tissue, cationic materials exhibited a significantly greater loss of neural tissue containing NeuN-positive neurons in the FBR non-neural tissue zone that immediately surrounded depots, resulting in overall larger lesions and greater loss of viable neuropil (Fig. 2d; Supplementary Fig. 5). Remarkably, despite significantly elevated CD13 in the nonneural compartments of cationic hydrogels (Fig. 2a-c), there was no significant difference in either CD13 (Fig. 2d; Supplementary Fig. 5) or GFAP (Fig. 2e) levels, and no detectable quantitative difference in NeuN-positive neuron density (Supplementary Fig. 5), in the neuropil adjacent to either cationic, nonionic or anionic hydrogels, suggesting that neural tissue beyond the interface between hydrogel and host was not substantively differentially impacted. The unexpected finding that GFAP levels were indistinguishable in neural tissue adjacent to hydrogels that evoked markedly different FBR at host interfaces indicates that GFAP staining is not a sensitive or sufficient marker with which to evaluate and differentiate FBRs.

Hydrogel FBRs differ in inflammatory cell recruitment/persistence. To discriminate among diverse innate-immune inflammatory cells involved in hydrogel FBRs, we used IHC for: (i) CD45 to identify leukocytes and reactive CNS microglia ${ }^{35}$; (ii) Iba-1 to identify blood-borne monocytes/macrophages and CNS microglia ${ }^{35}$; (iii) P2RY12 to identify only microglia ${ }^{20,36,37}$; (iv) Ly6B2 to identify neutrophils ${ }^{21}$; and (v) CD13 to identify myeloid lineage peripheral inflammatory cells such as monocytes and macrophages or fibroblast lineage cells (Fig. 3) ${ }^{28}$. We examined combinations of these markers at 1 week after hydrogel injections (Fig. 1b).

For all hydrogels, the neural tissue immediately adjacent to deposits contained reactive, CNS-derived microglia that were Iba1-, CD45-, and P2RY12-positive and CD13-negative that intermingled with astrocytes and neurons, remained within the neural tissue compartment and did not detectably infiltrate into any hydrogel (Fig. 3a, b; Supplementary Fig. 6a). P2RY12 expression was reduced in reactive microglia that dispersed directly within forming astroglia borders. Immediately abutting these microglia, hydrogel deposits exhibited variable intensities of inflammatory cell infiltrates that were CD45- and CD13-positive, and P2RY12-negative, and were peripherally derived myeloid lineage leukocytes and not CNS microglia (Fig. 3a, b, Supplementary Fig. 6a, b). A comparable segregation of blood-borne inflammatory cells into a non-neural tissue compartment away from neural tissue was also observed for the L-NIO stroke lesion (Supplementary Fig. 6c).

Different hydrogels exhibited remarkable variation in both the intensity and cellular phenotype of the blood-borne inflammatory response that they attracted. Non-ionic $\mathrm{DCH}_{\mathrm{MO}}$, which displayed a FBR comparable to all the other nonionic and anionic hydrogels evaluated, attracted only rare infiltrating CD45-positive leukocytes at interfaces with host tissue, and these were macrophage 


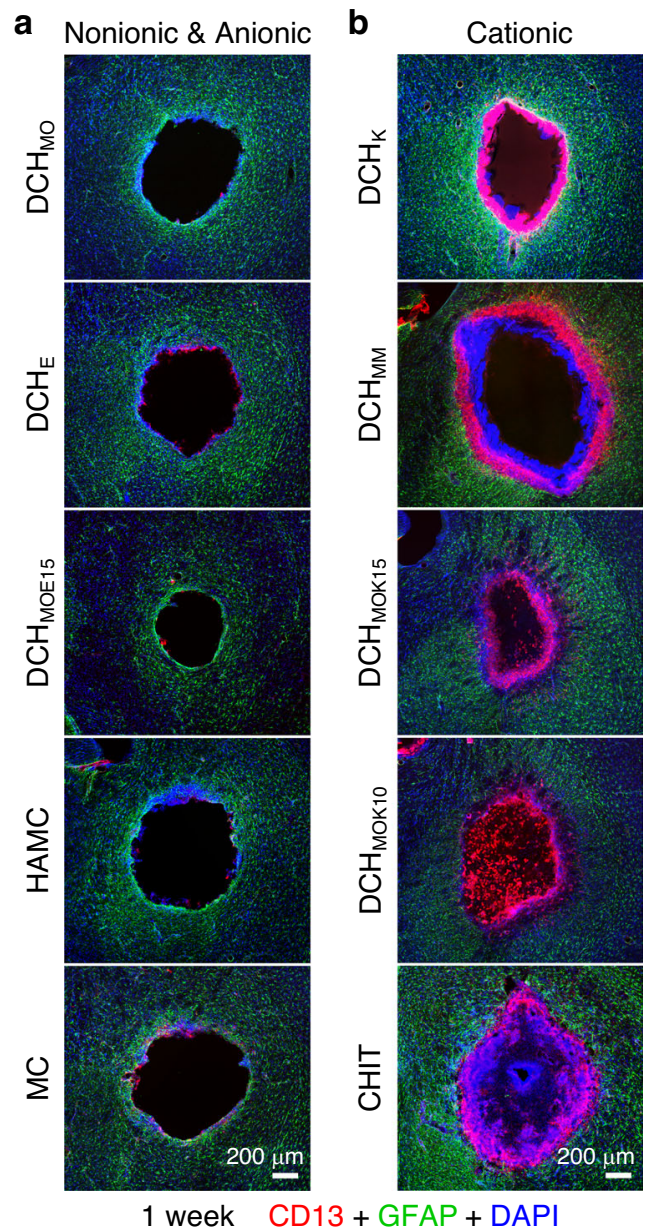

C
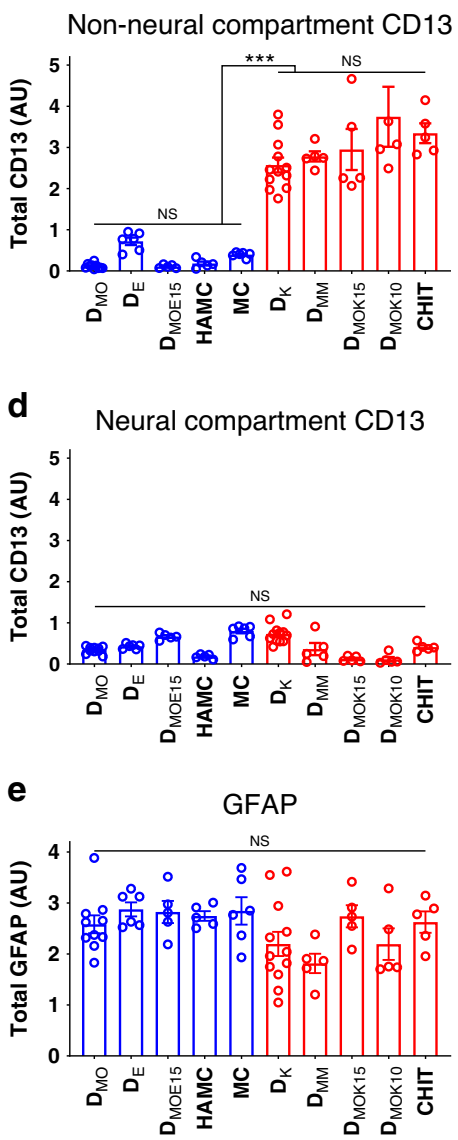

Fig. 2 Hydrogels that present cationic interfaces with host cells exhibit increased FBR severity. $\mathbf{a}$, b Survey images of stromal and inflammatory cells (CD13), astrocytes (GFAP), and all cell nuclei (DAPI) at 1 week after injection of nonionic and anionic $\mathbf{a}$, and cationic $\mathbf{b}$ hydrogels. c-e Quantification of total immunohistochemical staining. c, d Total CD13 in non-neural c and neural d tissue compartments. not significant (NS), ${ }^{\star \star \star} P<0.0001$, two-way ANOVA with Bonferroni. e Total GFAP in caudate putamen, NS, one-way ANOVA with Bonferroni. Graphs are mean \pm s.e.m with individual data points showing $n=$ $10,6,5,5,6,12,5,5,5,5$ mice per group for $\mathrm{DCH}_{M O}, \mathrm{DCH}_{\mathrm{E}}, \mathrm{DCH}_{\mathrm{MOE} 15}, \mathrm{HAMC}, \mathrm{MC}, \mathrm{DCH}_{\mathrm{K}}, \mathrm{DCH}_{\mathrm{MM}}$, DCH $\mathrm{MOK} 15_{15}$ DCH $\mathrm{MOK10}_{10}$ and $\mathrm{CHIT}$, respectively.

lineage (Iba-1-positive and CD13-positive) (Figs. 2a, 3a, b; Supplementary Fig. 6a). In contrast, cationic $\mathrm{DCH}_{\mathrm{K}}$ and $\mathrm{DCH}_{\mathrm{MM}}$ both attracted thick rims of infiltrating macrophage lineage cells (CD45-positive, Iba-1-positive, and CD13-positive) along their entire host interfaces (Figs. 2b, 3a, b; Supplementary Figs. 4, 6a). Immunohistochemical staining also revealed that the thick layers of DAPI-positive and CD13-negative cells infiltrating into $\mathrm{DCH}_{\mathrm{MM}}$ and CHIT (Fig. 2b) were leukocytes (CD45-positive), but were not macrophage lineage (Iba-1-negative) (Fig. 3a), and instead were highly phagocytic and cytotoxic Ly6B2-positive neutrophils (Fig. 3b, c; Supplementary Fig. 6b). In striking contrast, nonionic $\mathrm{DCH}_{\mathrm{MO}}$ and weakly cationic $\mathrm{DCH}_{\mathrm{MOK} 10}$ or anionic $\mathrm{DCH}_{\mathrm{MOE} 15}$, contained no detectable Ly6B2-positive neutrophils, whereas strongly cationic $\mathrm{DCH}_{\mathrm{K}}$ attracted a few of these cells (Fig. 3c, d; Supplementary Fig. 6a).

To test whether inflammatory response intensity correlated directly with strength of cationic charge at hydrogel surfaces, we measured zeta potentials of DCH hydrophilic polymer chains. $\mathrm{DCH}_{\mathrm{K}}$, containing homopolymers of lysine, had a significantly greater positive charge at physiological $\mathrm{pH}$ than $\mathrm{DCH}_{\mathrm{MM}}$ (containing statistical copolymers with $10 \%$ uncharged alanine) due to a higher total number of charged side chain groups along each hydrophilic chain (Supplementary Fig. 6d). However, $\mathrm{DCH}_{\mathrm{K}}$ had significantly lower levels of neutrophils and equivalent levels of macrophages compared to $\mathrm{DCH}_{\mathrm{MM}}$ (Fig. 3d). Non-ionic $\mathrm{DCH}_{\mathrm{MO}}$ had no detectable charge, no infiltration of neutrophils and only rare macrophages (Fig. 3a-c; Supplementary Fig. 6d).

Persistence of peripheral inflammatory cells at hydrogel deposits was evaluated at 3 weeks after injection (Supplementary Fig. 7a, b). Notably, while Ly6B2-positive neutrophils were mostly resolved at CHIT deposits by 3 weeks, thick rims of these acute inflammatory cells were sustained at $\mathrm{DCH}_{\mathrm{MM}}$ deposits with a distribution that was not obviously different to that at 1 week. $\mathrm{DCH}_{\mathrm{MM}}$ deposits also remained largely unresorbed at 3 weeks, whereas CHIT injections were completely infiltrated by cells at this timepoint (Supplementary Fig. 7c).

These findings show that the intensity and duration of the inflammatory cell components of CNS FBRs varied markedly in response to deposits of different hydrogels and that cationic charge at material-host interfaces is an important factor in attracting blood-borne phagocytic leukocytes. Nevertheless, charge magnitude alone does not determine the nature or distribution of phagocytes attracted.

Hydrogel FBRs involve stromal cells and fibrosis. To characterize fibrosis associated with hydrogel FBRs, we compared a representative hydrogel with limited detectable CD13 levels 
a

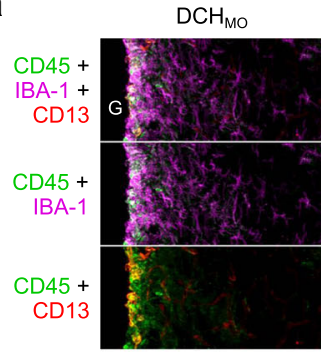

b

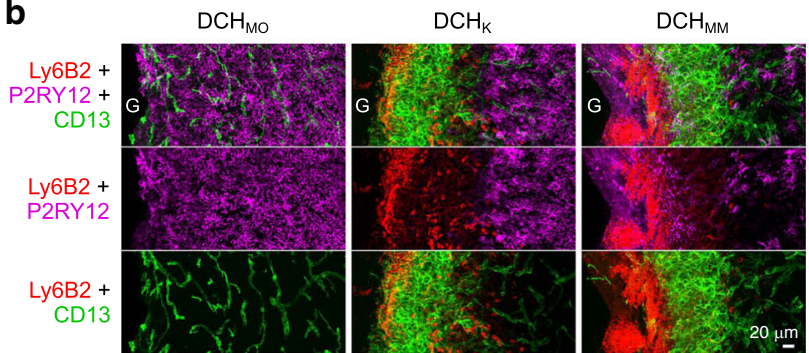

C
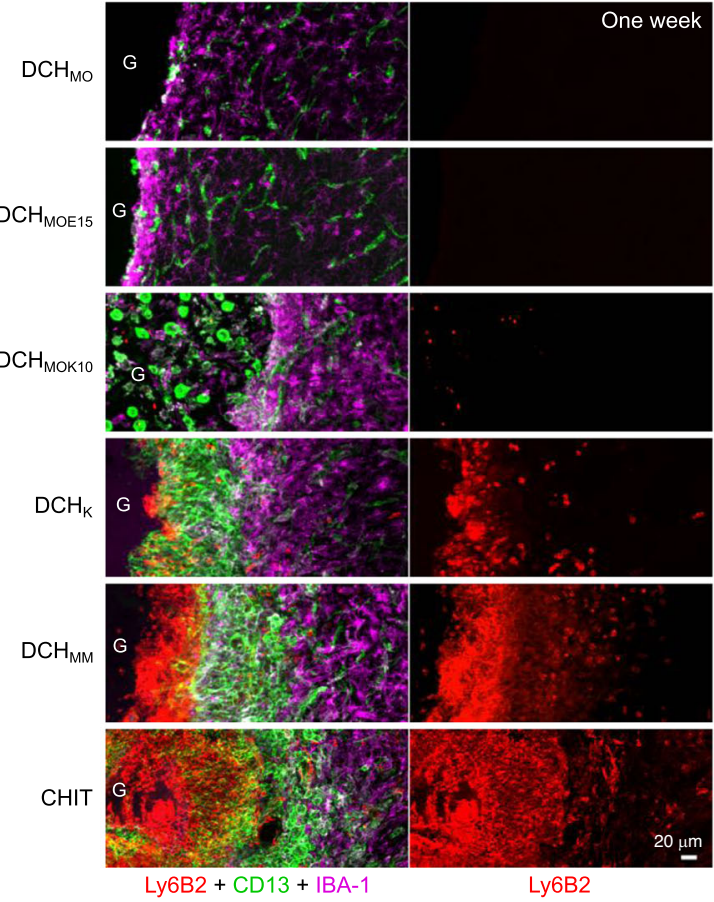

d

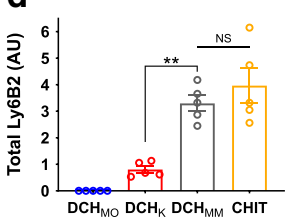

e

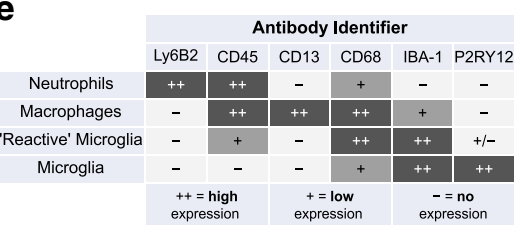

$\left(\mathrm{DCH}_{\mathrm{MO}}\right)$ to a representative hydrogel with a pronounced but focal rim of CD13 cells $\left(\mathrm{DCH}_{\mathrm{K}}\right)$ using IHC for cell surface and extracellular matrix molecules, collagen-1a1, fibronectin, laminin, and galectin-3 with staining for CD13 at various times after hydrogel injections (Figs. 1b, 4a-e). Collagen-1a1, fibronectin, and laminin demarcate stromal cells ${ }^{38}$, whereas galectin-3 can demarcate multiple cell types including stromal and inflammatory cells ${ }^{39-41}$. In uninjected normal neural tissue, (i) CD13stained stromal cells along blood vessels and at the meninges, (ii) collagen-1a1 and laminin lightly decorated cell surfaces along
Fig. 3 Different hydrogels attract inflammatory responses that differ in intensity and cellular phenotype. a Detail images of differences in inflammatory cell recruitment 1 week after injection of $\mathrm{DCH}_{\mathrm{MO}}, \mathrm{DCH}_{\mathrm{K}}$, $\mathrm{DCH}_{\mathrm{MM}}$ hydrogels (G). b Detail images showing that CNS-derived P2RY12positive microglia do not migrate into non-neural tissue compartments in spite of different FBRs evoked by $\mathrm{DCH}_{\mathrm{MO}}, \mathrm{DCH}_{\mathrm{K}}, \mathrm{DCH}_{\mathrm{MM}}$. c Detail images of hydrogel-tissue interface showing the escalating recruitment and persistence of Ly6B2-positive neutrophils at cationic hydrogel surfaces at 1 week after injection. d Quantification of total Ly6B2 staining for hydrogels 1 week after injection. Not significant (NS) and ${ }^{\star \star} P=0.0011$ for CHIT and $\mathrm{DCH}_{K}$ versus $\mathrm{DCH}_{\mathrm{MM}}$, respectively, one-way ANOVA with Bonferroni. e Table summarizing the combination of antibodies used to identify different inflammatory cell types. Graphs show mean \pm s.e.m with individual data points showing $n=5$ mice per group.

blood vessels and around neurons, (iii) fibronectin was present at large vessels and at the meninges, and (iv) galectin-3 was essentially undetectable ${ }^{42}$ (Supplementary Fig. 8a).

At 1 week after injection, tissue adjacent at interfaces with nonionic $\mathrm{DCH}_{\mathrm{MO}}$ exhibited staining for collagen-1a1 and laminin only along blood vessels in a manner similar to normal neural tissue, whereas fibronectin and galectin-3 were moderately elevated in narrow rims along host-gel interfaces (Fig. 4a, c-e). In contrast, the thick capsule of CD13-positive cells circumscribing cationic $\mathrm{DCH}_{\mathrm{K}}$ exhibited significantly greater levels of collagen-1a1, laminin, fibronectin, and galectin-3 (Fig. 4b, c). Around $\mathrm{DCH}_{\mathrm{K}}$, galectin-3 was robustly expressed by essentially all CD13-positive cells, whereas collagen-1a1, laminin, and fibronectin demarcated subsets of stromal cells in outer margins (Fig. 4b) that interfaced directly with the forming astrocyte limitans border. An interior layer of CD13- and galectin-3positive but collagen-1a1, fibronectin, and laminin-negative cells, likely peripheral inflammatory cells, interacted directly with the $\mathrm{DCH}_{\mathrm{K}}$ surface (Fig. 4b). This inflammatory and fibrotic cell stratification around $\mathrm{DCH}_{\mathrm{K}}$ is reminiscent of the cellular organization in CNS abscesses and traumatic injury lesions ${ }^{40,43}$. CD13- and galectin-3-positive cells persisted chronically in the non-neural tissue compartment of resorbed $\mathrm{DCH}_{\mathrm{K}}$ for at least 6 weeks (Fig. 4f). Interestingly, the GFAP-positive astrocyte limitans border that formed the direct host interface with nonionic $\mathrm{DCH}_{\mathrm{MO}}$ also extensively expressed galectin-3 and this expression persisted chronically for at least 6 weeks (Fig. 4d, e; Supplementary Fig. 8b).

These findings show that $\mathrm{DCH}_{\mathrm{MO}}$ evokes minimal levels of fibrosis, whereas cationic $\mathrm{DCH}_{\mathrm{K}}$ evokes a stronger fibrotic FBR with elevated levels of multiple matrix molecules at the interface with preserved neural tissue. In addition, we identified a possible conserved function for galectin-3 in isolating foreign bodies from parenchymal neural tissue regardless of the severity of the FBR, with its expression occurring rapidly following hydrogel injection and present only in cells forming the material-tissue interface, regardless of cell type (inflammatory cells, stromal cells, or astrocytes). Galectin-3 is known to be associated with fibrosis and wound healing in various tissue injuries including kidney, liver, and heart ${ }^{44}$ and is significantly upregulated in macrophages/ microglia and reactive astrocytes after various traumatic CNS injuries $^{42,45-47}$. Here, we identify galectin-3 to also be an important constituent of CNS FBRs to materials.

Tissue damage drives FBR and causes acute amyloid formation. We next looked for associations between FBR, inflammation, fibrosis and host tissue loss, and for other potential molecular features shared across FBR and CNS wound response. 
a

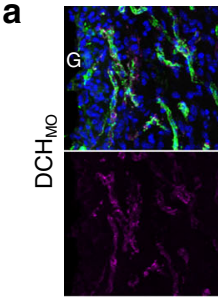

b
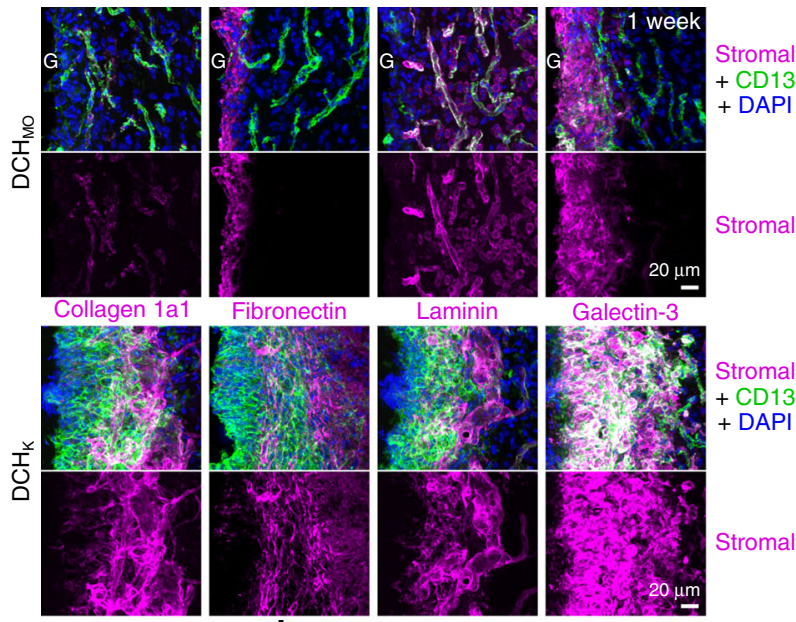

C

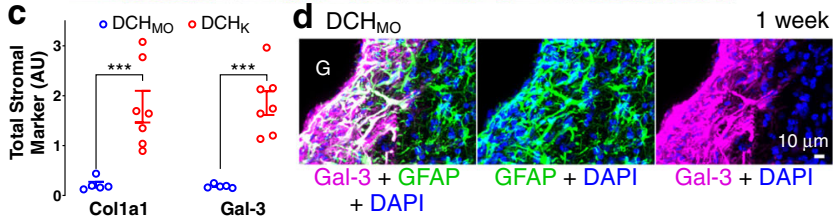

e
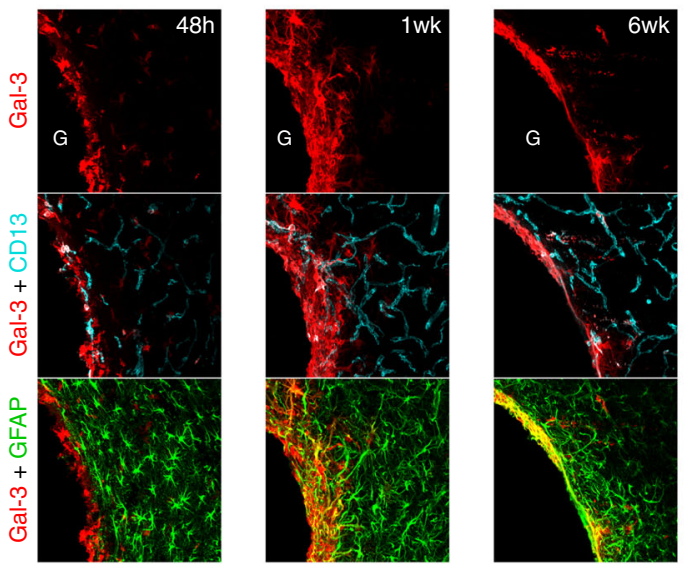

$\mathbf{f}$
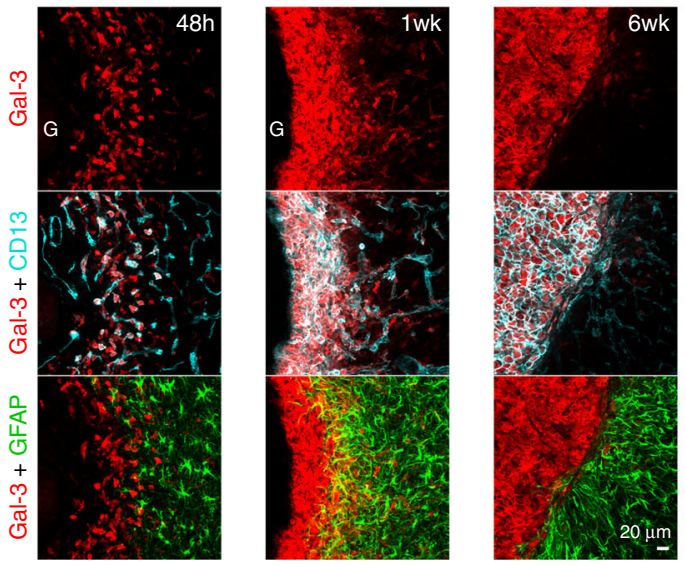

To do so, we first used mice expressing reporter protein transgenically targeted to host astrocytes via Aldh1l1-Cre-ERT2 and evaluated host neural tissue damage and changes in various molecular markers, including accumulation of amyloid precursor protein (APP), a robust marker of axonal injury ${ }^{48}$ and one of its breakdown products, beta-amyloid $(\mathrm{A} \beta)^{49}$. We compared representative hydrogels displaying minimal or pronounced FBRs with the CNS wound response to L-NIO stroke lesions at various timepoints.
Fig. 4 Hydrogels evoke fibrotic responses at the material-tissue interface that can involve stromal or astroglial cells. $\mathbf{a}$, $\mathbf{b}$ Detail images of stromalassociated markers, collagen-1a1 (Col1a1), fibronectin, laminin, and galectin3 (Gal-3) and their relationship to non-neural CD13-positive cells at the tissue interface of $\mathrm{DCH}_{\mathrm{MO}} \mathbf{a}$ and $\mathrm{DCH}_{\mathrm{K}} \mathbf{b}$ at 1 week after injection (hydrogels, G). Colocalization of markers with CD13-positive cells is seen as white staining. c Quantification of total Col1a1 and Gal-3 staining at 1 week after hydrogel injection. ${ }^{\star \star \star} P=0.0003$ and $=0.0002$ for $\mathrm{DCH}_{\text {MO }}$ versus $\mathrm{DCH}_{\mathrm{K}}$ for Colla1 and Gal-3 stromal markers, respectively, two-way ANOVA with Bonferroni. Graphs show mean \pm s.e.m with individual data points showing $n=5$ and 7 mice for $D \mathrm{DH}_{M O}$ and $D \mathrm{DH}_{K}$, respectively. $\mathbf{d}$ Detail image showing that adjacent to $\mathrm{DCH}_{\mathrm{MO}}$, Gal-3 colocalizes with a narrow band of GFAP-positive astrocytes that border the gel at 1 week. Gal3 and GFAP colocalization is seen as white staining. e, $\mathbf{f}$ Detail images showing the temporal evolution of Gal-3 expression at the interface of $\mathrm{DCH}_{\mathrm{MO}} \mathbf{e}$ and $\mathrm{DCH}_{\mathrm{K}} \mathbf{f}$ at acute $(48 \mathrm{~h}, 48 \mathrm{~h}$ ), subacute (1 week, 1wk) and chronic ( 6 weeks, $6 w k$ ) timepoints after injection. Gal-3 and GFAP colocalization is seen as yellow staining. Gal-3 and CD13 colocalization is seen as white staining.

At $48 \mathrm{~h}$ after injection, $\mathrm{DCH}_{\mathrm{MO}}$ exhibited a minimal zone of host neural tissue loss averaging only $25 \mu \mathrm{m}$, the equivalent of one or two cells in thickness, whereas $\mathrm{DCH}_{\mathrm{K}}$ exhibited a significantly greater, but still relatively small zone of host neural tissue loss of $\sim 150 \mu \mathrm{m}$ in thickness, as evidenced by: (i) astrocyte and neuron loss but persistence of vasculature, (ii) presence and phagocytosis of reporter protein debris, (iii) extravasation of blood-borne fibronectin ${ }^{50}$, (iv) upregulation of CD13 expression along thin PECAM-1-positive blood vessels within the damaged tissue zone, and (v) infiltration of blood-borne phagocytic leukocytes (Fig. 5a, b; Supplementary Fig. 9a-e).

Further characterization of the extent of axonal injury was provided by APP staining. APP is low or undetectable by IHC in healthy CNS tissue, but increases markedly after axonal injury ${ }^{48,51}$. After $48 \mathrm{~h}, \mathrm{DCH}_{\mathrm{MO}}$ displayed only small amounts of APP accumulation at the hydrogel-host interface (Fig. 5c). In contrast, APP was present throughout the narrow zone of neural tissue damage induced by $\mathrm{DCH}_{\mathrm{K}}$ and APP accumulation was prominent in damaged axon bundles close to $\mathrm{DCH}_{\mathrm{K}}$ deposits in a manner comparable with L-NIO stroke lesions (Fig. 5c). By one week, APP staining had decreased substantially and was detectable only at the interface of neural to non-neural tissue, and APP had returned to baseline at 6 weeks across all conditions (Fig. 5c).

The formation of A $\beta$ via cleavage of APP by $\beta$ - and $\gamma$-secretase enzymes is increasingly recognized as a normal occurrence during CNS wound responses ${ }^{52,53}$. We evaluated the progression of APP to $A \beta$ (Fig. $5 \mathrm{~d}$ ). At $48 \mathrm{~h}, \mathrm{~A} \beta$ was sparse at the hydrogel-tissue interface for both $\mathrm{DCH}_{\mathrm{MO}}$ and $\mathrm{DCH}_{\mathrm{K}}$, whereas $\mathrm{L}-\mathrm{NIO}$ stroke lesions already showed clear $\mathrm{A} \beta$ accumulation at the borders of infarcted and spared neural tissue (Fig. 5d). By one week, A $\beta$ was barely detectable around $\mathrm{DCH}_{\mathrm{MO}}$ and was comparable to $\mathrm{PBS}$ injections where $A \beta$ was constrained to the track of tissue disrupted by the injection pipette (Supplementary Fig. 10a, b). At 1 week after $\mathrm{DCH}_{\mathrm{K}}, \mathrm{DCH}_{\mathrm{MM}}$ injections and L-NIO stroke lesions, $\mathrm{A} \beta$ accumulation was most prominent within the layers of CD13positive inflammatory cells that infiltrated areas of neural tissue damage (Fig. 5d, e). In addition, in all conditions, there was prominent colocalization of $\mathrm{A} \beta$ within Iba-1-positive reactive microglia in adjacent spared neural tissue, suggesting phagocytosis by these cells as well (Fig. 5e, Supplementary Fig. 10c). Quantification confirmed significantly higher levels of $\mathrm{A} \beta$ at one week for $\mathrm{DCH}_{\mathrm{K}}$ and $\mathrm{DCH}_{\mathrm{MM}}$ compared with $\mathrm{DCH}_{\mathrm{MO}}$ (Fig. 5e, f). Increased neutrophil accumulation and persistence in $\mathrm{DCH}_{\mathrm{MM}}$ 
compared with $\mathrm{DCH}_{\mathrm{K}}$ (Fig. 3c, d) was not associated with any increase in $A \beta$ formation (Fig. 5e, $f$ ), suggesting that $A \beta$ is formed as a result of acute neural tissue injury and not by ongoing chronic inflammation. At 6 weeks, A $\beta$ levels had reduced markedly and were evident only within the persistent nonneural tissue lesions for $\mathrm{DCH}_{\mathrm{K}}$ and L-NIO stroke (Fig. 5d).

These finds show that the inflammatory and fibrotic FBRs evoked by cationic hydrogels were driven by narrow but measurable zones of host neural tissue damage occurring along hydrogel-host interfaces soon after injection and that this was essentially absent with the nonionic $\mathrm{DCH}_{\mathrm{MO}}$. These findings also show that APP accumulation and $\mathrm{A} \beta$ formation around hydrogel deposits occurred as a result of damage to neural tissue and axonal injury. These observations are consistent with growing evidence that APP accumulation and subsequent $A \beta$ formation are part of a conserved innate wound and FBR. Although the specific functions of $A \beta$ production in this context are not yet defined, recent evidence suggests that $A \beta$ may exert antimicrobial activities $^{52,53}$.

Astrocyte limitans borders isolate FBRs from neural tissue. Neural tissue contains several types of glial cells that become reactive around damaged CNS tissue and participate in FBRs. Astrocytes are well known to form "scar borders" that serve as limitans borders to isolate CNS lesions ${ }^{19}$. Microglia contribute to border formation and exert phagocytic functions ${ }^{20}$, whereas oligodendrocyte progenitors (OPC) proliferate and repair myelin ${ }^{22}$. We identified astrocytes and microglia by IHC for GFAP and P2RY12, respectively, and OPC by staining for OLIG2 and the reporter protein, td-Tomato $(\mathrm{tdT})$, which had been transgenically targeted by NG2(CSPG4)-Cre-ERT2 ${ }^{54}$. We compared combinations of markers and probed blood-brain barrier (BBB) integrity at 1 and 6 weeks after hydrogel injection or L-NIO stroke (Figs. 6 and 7).

GFAP-positive astrocytes had begun to form distinct borders around all hydrogel deposits by 1 week after injections, and these borders persisted and consolidated by 6 weeks. Astrocyte borders around hydrogels were similar in appearance to borders formed around L-NIO infarcts and clearly segregated persisting hydrogel material and CD13-positive stromal and inflammatory cells from neural tissue containing NeuN-positive neurons (Figs. 1c, d; 2a, b; $6 \mathrm{a}, \mathrm{b} ; 7 \mathrm{a}, \mathrm{b})$. Notably, astrocyte borders adjacent to $\mathrm{DCH}_{\mathrm{MO}}$ and other nonionic hydrogels interfaced directly with gel surfaces with limited intervening fibrosis or inflammation, whereas astrocyte borders adjacent to $\mathrm{DCH}_{\mathrm{K}}$ and other cationic gels or L-NIO interfaced with stromal and inflammatory cells (Figs. 2a, b, 4, 6a, b). Astrocyte borders around hydrogels and L-NIO infarcts were similar in appearance to astrocyte limitans borders that separate healthy neural tissue from non-neural stromal cells along all interfaces of normal CNS with meninges (Supplementary Fig. 1c) ${ }^{55}$. Astrocyte border thickness at 6 weeks was proportionally greater with increasing severity of $\mathrm{FBR}$, such that $\mathrm{DCH}_{\mathrm{MO}}$ displayed the thinnest astrocyte borders while $\mathrm{DCH}_{\mathrm{K}}$ and L-NIO both had similar sized borders of more than double the thickness (Fig. 7e). Across all conditions at 6 weeks, lateral astrocyte borders formed by gray matter astrocytes, were thinner compared with medial borders that recruited white matter astrocytes from the internal capsule (Figs. 1b, $7 \mathrm{a}, \mathrm{b}, \mathrm{e})$.

Neural parenchyma extending from astrocyte borders exhibited initially moderate astrocyte reactivity indicated by elevated GFAP, which declined significantly over time and by 6 weeks was minimal in all cases (Figs. 6a, b; 7a, b). Reactive microglia and OPC intermingled with astrocytes along borders and adjacent neural tissue, but did not infiltrate into hydrogels or contribute to volumes of CD13-positive fibrosis and inflammation at any timepoint examined (Fig. 6a-d and Supplementary Fig. 11a). At 6 weeks a thin, single cell layer of non-neural tissue (CD13positive) that expressed stromal cell markers PDGFR $\beta$ and fibronectin interfaced directly with $\mathrm{DCH}_{\mathrm{MO}}$ and the astrocyte limitans border (Supplementary Fig. 11b), whereas these cells contributed to large volumes of non-neural fibrotic tissue in $\mathrm{DCH}_{\mathrm{K}}$ and L-NIO strokes (Supplementary Fig. 11b, c).

Astrocyte border formation is essential for re-establishing $\mathrm{BBB}$ integrity after CNS injuries ${ }^{30}$. To probe $\mathrm{BBB}$ integrity adjacent to hydrogel deposits, we stained for mouse immunoglobulin (IgG) and albumin, the two most abundant serum proteins ${ }^{30}$. As expected, after 1 week and prior to border formation ${ }^{30}$, IgG, and albumin staining were increased in neural parenchyma around hydrogel injections and L-NIO stroke lesions, and were significantly higher around $\mathrm{DCH}_{\mathrm{K}}$, compared with $\mathrm{DCH}_{\mathrm{MO}}$ (Fig. 6e, f; Supplementary Fig. 12a-c). By 6 weeks, serum protein levels around $\mathrm{DCH}_{\mathrm{MO}}$ were indistinguishable from those in uninjured tissue and were restricted to a thin layer of non-neural tissue that interfaced with the astrocyte limitans border. In contrast, around L-NIO stroke lesions and cationic $\mathrm{DCH}_{\mathrm{K}}$, serum proteins remained significantly elevated in neural tissue at 6 weeks (Fig. 6e, f, Supplementary Fig. 12a-c).

These findings show that astrocytes rapidly form limitans borders around hydrogels in a manner similar to borders formed around ischemic or traumatic tissue damage, or that exist along meningeal non-neural stromal tissue around healthy CNS. Astrocytes, microglia, and OPCs become reactive in neural tissue adjacent to hydrogel deposits or stroke lesions, but do not migrate into the non-neural fibrotic tissue compartments that persist chronically. Glial reactivity and BBB leakiness into neural tissue adjacent to astrocyte borders persist longer adjacent to cationic materials that generate substantial inflammation and fibrosis compared with nonionic materials that do not.

FBR determines hydrogel resorption or persistence. To evaluate the relationship between FBR and hydrogel resorption or persistence, we compared nonionic $\mathrm{DCH}_{\mathrm{MO}}$ and cationic $\mathrm{DCH}_{\mathrm{K}}$ deposits at various times after injection (Figs. 1 and 7). Quantification showed that after $48 \mathrm{~h}, \mathrm{DCH}_{\mathrm{MO}}$, and $\mathrm{DCH}_{\mathrm{K}}$ exhibited deposits of similar size. After 1 week, $\mathrm{DCH}_{\mathrm{MO}}$ deposits had decreased in size by $30 \%$, but remained at this size after 6 weeks and persisted essentially unchanged after 12 weeks (Fig. 7a-d, f). In contrast, after 1 week $\mathrm{DCH}_{\mathrm{K}}$ deposits had decreased in size significantly by over $50 \%$ and continued to steadily decrease in size until there was no detectable deposit remaining at 6 weeks (Fig. 7a, b, f). Over time, $\mathrm{DCH}_{\mathrm{MO}}$ exhibited no increase in CD13 levels above baseline, whereas $\mathrm{DCH}_{\mathrm{K}}$ evoked a steadily increasing infiltration of CD13-positive inflammatory and stromal cells that proceeded in a concentric fashion from hydrogel-tissue interfaces inwards until the entire deposit was consumed (Figs. 1c, d, 3a, 4b, 7a, b, g; Supplementary Fig. 7a). By comparison, the wound response to L-NIO-induced ischemia attracted a pronounced infiltration of CD13-positive cells that rapidly filled the entire volume of damaged tissue and then persisted (Figs. 1c, d, 7a, b).

These findings show that $\mathrm{DCH}_{\mathrm{MO}}$ and other nonionic hydrogels persist and are not efficiently resorbed in vivo because they do not attract sufficient CD13-positive phagocytes. In contrast, $\mathrm{DCH}_{\mathrm{K}}$ and other cationic hydrogels attract these phagocytic leukocytes to their interfaces with host tissue and are gradually resorbed from the outside in and become replaced by fibrosis. $\mathrm{DCH}_{\mathrm{MM}}$ was an exception to this general cationic hydrogel resorption trend and instead showed minimal hydrogel resorption after 3 weeks (Supplementary Fig. 7c). This chronic hydrogel persistence coupled with the unresolved Lys6B2-positive neutrophils at the material-tissue interface suggests that $\mathrm{DCH}_{M M}$ 
a

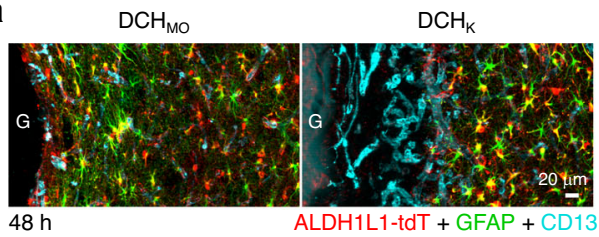

C
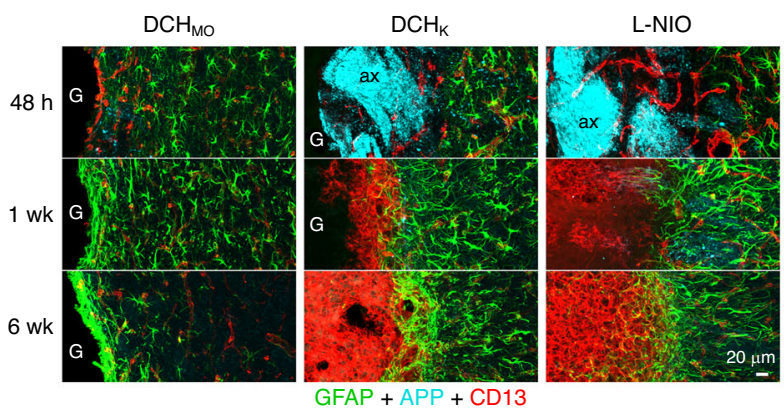

d
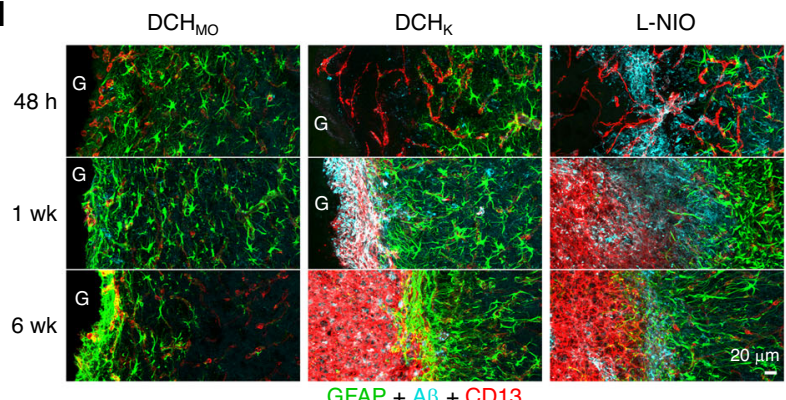

e
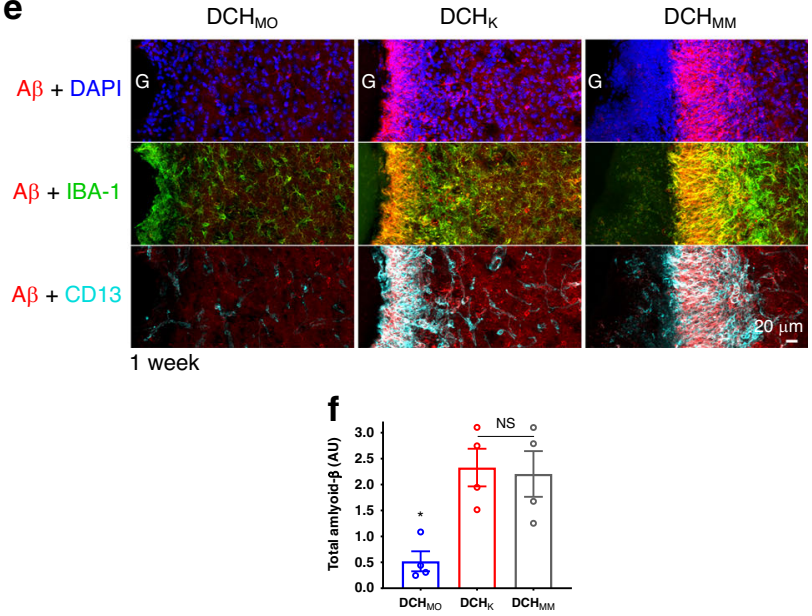

is unable to be readily cleared due to frustrated phagocytosis, possibly owing to toxicity towards or repulsion of phagocytosing cells. Thus, hydrogel properties determine FBR features, which in turn determine hydrogel resorption or persistence.

Microparticles alter FBR and hydrogel resorption. Incorporating nano/microparticles (MPs) into hydrogels may be a useful tool to enhance the control of delivery of multiple and diverse molecular cargos independently from a single construct to the $\mathrm{CNS}^{18,56,57}$. As introduction of particles may alter the physiochemical properties of hydrogels into which they are loaded, we examined the effects on FBR and resorption of hydrogels laden with polyethylene glycol (PEG)-based nonionic MP formulated via a standard inverse emulsion thiol-ene Michael addition
Fig. 5 Hydrogel FBR severity is determined by the extent of acute neural tissue damage at the material interface, which is associated with axonal damage, APP accumulation, and amyloid formation. a Detail images of the material-tissue interface for $\mathrm{DCH}_{\mathrm{MO}}$ and $\mathrm{DCH}_{\mathrm{K}}$ at $48 \mathrm{~h}$ after injection. ALDH1L1-tdT reporter and GFAP identify host astrocytes and the loss of these cells demarcates regions of host tissue damage. At 48 h, CD13positive cells in this damaged tissue region predominately label actively remodeling vasculature. $\mathbf{b}$ Quantification of radial thickness of tissue damage around $\mathrm{DCH}_{\mathrm{MO}}$ and $\mathrm{DCH}_{\mathrm{K}}\left(n=9\right.$ mice per group). ${ }^{\star \star \star} P=0.0001$ Welch's (unequal variance) two-tailed $t$ test $(t=6.56, d f=8.74)$.

c, d Detail images for $\mathrm{DCH}_{\mathrm{MO}}, \mathrm{DCH}_{\mathrm{K}}$, and L-NIO-induced stroke at acute ( $48 \mathrm{~h}, 48 \mathrm{~h}$ ), subacute (1 week, 1wk), and chronic (6 weeks, 6wk) timepoints after injection, comparing staining for amyloid precursor protein (APP) $\mathbf{c}$ or amyloid-beta (A $\beta$ ) d with GFAP and CD13. e Images show $A \beta$, Iba-1, and $\mathrm{CD} 13$ at the interface of $\mathrm{DCH}_{\mathrm{MO}}, \mathrm{DCH}_{\mathrm{K}}$, and $\mathrm{DCH}_{\mathrm{MM}}$ with host tissue at 1 week after injection. $\mathbf{f}$ Quantification of $A \beta$ at 1 week after $\mathrm{DCH}_{\mathrm{MO}}, \mathrm{DCH}_{\mathrm{K}}$ and $\mathrm{DCH} \mathrm{H}_{\mathrm{MM}}$. NS or ${ }^{\star} P=0.0153$ and $=0.0227$ for $\mathrm{DCH}_{\mathrm{MO}}$ versus $\mathrm{DCH}_{\mathrm{K}}$ and $\mathrm{DCH}_{\mathrm{MM}}$, respectively, one-way ANOVA with Bonferroni, $n=4$ mice per group. All graphs shows mean \pm s.e.m with individual data points superimposed. $G$ hydrogels, ax axons.

process (Fig. $7 \mathrm{~h})^{58-60}$. MP, with an average diameter of $3.3 \mu \mathrm{m}$, imparted a modest increase in mechanical properties to $\mathrm{DCH}$ but did not alter injectability (Supplementary Fig. 13a-f). MP at high concentrations were non-toxic to neural progenitor cells in vitro (Supplementary Fig. 13d). As described above, nonionic $\mathrm{DCH}_{\mathrm{MO}}$ and HAMC on their own evoked minimal fibrotic or inflammatory responses and formed long persisting deposits. Addition of nonionic MP to these hydrogels caused pronounced recruitment of peripheral inflammatory cell infiltration in the form of both CD13-positive macrophages and Lys6B2-positive neutrophils, as well as rapid hydrogel resorption and fibrotic replacement (Fig. 7i-k; Supplementary Fig. 13g-k). Nevertheless, the FBR of MP loaded $\mathrm{DCH}_{\mathrm{MO}}$ did not detectably increase acute neural tissue loss or axonal injury (Supplementary Fig. 13g, h). Similar sized non-toxic MP as the ones evaluated here $(\sim 3 \mu \mathrm{m}$ diameter) have previously demonstrated a high susceptibility to phagocytosis in vitro by macrophages ${ }^{61}$. Incorporating MP into nonionic hydrogels may stimulate similar size recognition programs in vivo thus leading to the recruitment of phagocytes by mechanisms other than those associated with host neural tissue damage at the hydrogel-host interface as was the case for cationic hydrogels. These findings show that adding such MP to hydrogels that would otherwise be ignored by phagocytes can induce a phagocytic FBR that steadily resorbs the material and replaces it with fibrosis.

FBR alters hydrogel molecular delivery to CNS parenchyma. To characterize FBR effects on delivery of molecular cargos, we first examined the biodistribution of model non-bioactive molecules released into neural tissue adjacent to hydrogel deposits, and second evaluated the efficacy of bioactive growth factor delivery. As non-bioactive molecules, we used biotinylated dextran amines (BDA) of different molecular weights because they are nonimmunogenic, fixable, easily detected by IHC, and because 10 $\mathrm{kDa}$ (BDA-10) and $70 \mathrm{kDa}$ (BDA-70) BDAs exhibit hydrodynamic radii that approximate bioactive protein growth factors and therapeutic monoclonal antibodies, respectively ${ }^{62,63}$.

BDAs injected in PBS are well documented to diffuse locally throughout CNS neural parenchyma and along perivascular spaces, and are taken up by neurons as well as by microglial and perivascular phagocytic cells in a size dependent manner ${ }^{64}$. A detailed comparison of the biodistributions of BDA-10 and BDA- 
a
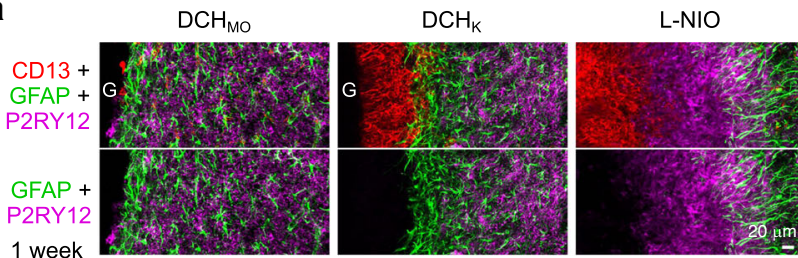

b
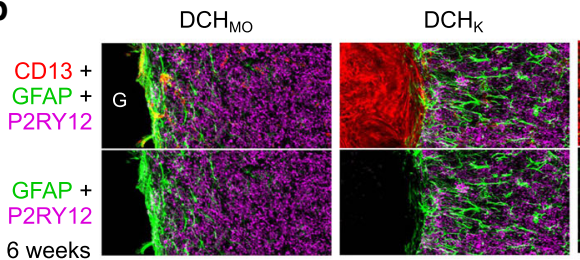

L-NIO

C

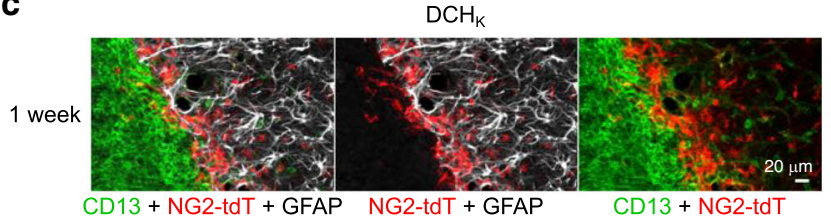

d
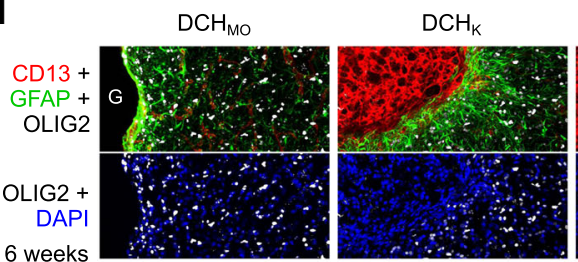

L-NIO

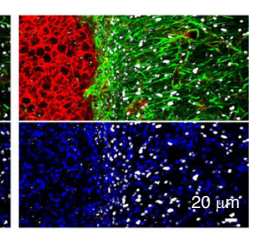

e

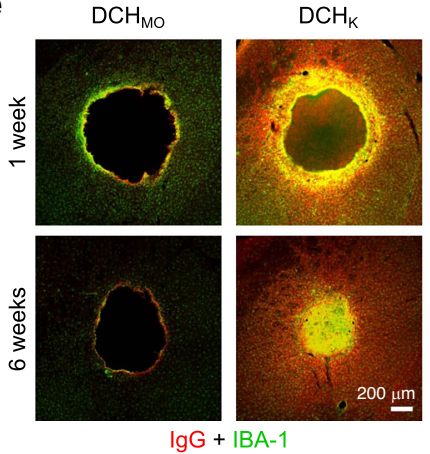

$\mathbf{f}$

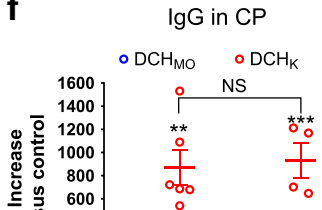

Fig. 6 Astrocytes form limitans borders that isolate hydrogels and nonneural FBR components from viable neural tissue. $\mathbf{a}$, $\mathbf{b}$ Progression of astrocyte limitans border formation from 1 week $\mathbf{a}$ to 6 weeks $\mathbf{b}$ for $\mathrm{DCH}_{\mathrm{MO}}$, $\mathrm{DCH}_{\mathrm{K}}$, and L-NIO-induced stroke. c, d OPC identified by NG2-targeted reporter (tdT) c and Olig2 $\mathbf{d}$ intermingle with GFAP-positive astrocytes and do not migrate into CD13-positive regions. e Comparison of extent of blood-brain barrier (BBB) disruption and repair as measured by IgG staining around $\mathrm{DCH}_{\mathrm{MO}}$ and $\mathrm{DCH}_{\mathrm{K}}$ deposits at 1 and 6 weeks after injection. $\mathbf{f}$ Quantification of the percentage increase in lgG levels in the hydrogel injected caudate putamen $(\mathrm{CP})$ normalized to the non-injected contralateral side. ${ }^{\star \star} P=0.0012$ and ${ }^{\star \star \star} P=0.0001$ for $\mathrm{DCH}_{\mathrm{K}}$ versus $\mathrm{DCH}$ MO at 1 week and 6 week, respectively, and not significant (NS) for $\mathrm{DCH}_{K}$ samples between the two timepoints, two-way ANOVA with Bonferroni. Graph shows mean \pm s.e.m with individual data points superimposed showing $n=$ 5 and 6 mice for $\mathrm{DCH}_{\mathrm{MO}}$ and $\mathrm{DCH}_{\mathrm{K}}$, respectively.

70 released from $\mathrm{PBS}, \mathrm{DCH}_{\mathrm{MO}}$, or $\mathrm{DCH}_{\mathrm{K}}$ is presented in Supplementary Figs. 14-16. In brief, under all conditions, BDAs were detectable only in the ipsilateral hemisphere. Notably, delivery of BDAs of either size via $\mathrm{DCH}_{\mathrm{MO}}$ or $\mathrm{DCH}_{\mathrm{K}}$ resulted in significant differences both in the depth of penetration of BDAs into neural tissue and in cellular uptake such that BDAs of either size released from $\mathrm{DCH}_{\mathrm{MO}}$ were found to be more concentrated locally near hydrogel deposits, whereas BDAs released from $\mathrm{DCH}_{\mathrm{K}}$ showed increased radial diffusion (Supplementary Figs. 14-16), (Supplementary Fig. 16). BDAs of different sizes showed dissimilar cellular uptake profiles such that BDA-70 was consumed preferentially by phagocytes in neural tissue while BDA-10 showed enhanced neuron uptake. Nevertheless, the hydrogel used for delivery also had substantial effects on cellular uptake of each BDA (Supplementary Fig. 16). BDA-70 showed low but clearly detectable uptake by neurons when released from $\mathrm{DCH}_{\mathrm{MO}}$ but no neuron uptake when released from $\mathrm{DCH}_{\mathrm{K}}$. BDA10 released from $\mathrm{DCH}_{\mathrm{MO}}$ showed extensive uptake by neurons as well as axon labeling throughout the adjacent neuropil and low accumulation in phagocytes. By contrast, BDA-10 released from $\mathrm{DCH}_{\mathrm{K}}$ showed low uptake by neurons, no obvious axon labeling and pronounced uptake by phagocytes (Supplementary Figure 16). These differences may relate to the increased activation and number of microglia in neural tissue adjacent to $\mathrm{DCH}_{\mathrm{K}}$ deposits, which could either stochastically or actively favor greater uptake of BDA-10 by phagocytes over neurons. These findings indicate that hydrogels with different FBRs exhibit differences not only in the distribution of molecular delivery into neural tissue, but also in the type of cells that may be primarily targeted.

We therefore next compared the biodistribution of BDA-10 released from different hydrogels that displayed escalating and unique severities of FBR: $\mathrm{DCH}_{\mathrm{MO}}, \mathrm{DCH}_{\mathrm{K}}, \mathrm{DCH}_{\mathrm{MM}}$, and CHIT (Fig. 8a). We quantified the proportion of $\mathrm{BDA}$ present in the non-neural compartment defined as the area of hydrogel deposit and its non-neural surrounding tissue, versus the neural compartment defined as the neural tissue surrounding the deposits containing viable neurons and different neuroglia (Fig. 8b-d, Supplementary Fig. 17). At 2 weeks after injection, $\mathrm{DCH}_{\mathrm{MO}}$, with the least noxious FBR showed the highest total delivery of BDA into the neural compartment, and yielded greater uptake in neurons, which was highest local to the hydrogel-tissue interface (Fig. 8b-d). $\mathrm{DCH}_{\mathrm{K}}$ exhibited less neural parenchyma delivery than $\mathrm{DCH}_{\mathrm{MO}}$ but more than $\mathrm{DCH}_{\mathrm{MM}}$ and CHIT, and BDA was preferentially taken up by microglia rather than neurons (Fig. 8e, f). $\mathrm{DCH}_{\mathrm{MM}}$ and CHIT, which show the most severe FBR (Fig. 3b, d), displayed: (i) significantly increased accumulation of BDA in non-neural compartments associated with the FBR (Fig. 8b); (ii) reduced uptake of BDA by local neurons (Fig. 8c); and (iii) greater BDA accumulation in macrophages (CD13-positive/CD68-positive cells) (Fig. 8e). Notably, $\mathrm{DCH}_{\mathrm{K}}, \mathrm{DCH}_{\mathrm{MM}}$ and CHIT exhibited pronounced BBB leakage with extended distribution of serum albumin through neural parenchyma compared with $\mathrm{DCH}_{\mathrm{MO}}$ (Supplementary Fig. 17c, d) and degree of BBB leak correlated with increased BDA biodistribution throughout the brain and increased inflammatory cell phagocytosis of BDA (Fig. 8d, e, Supplementary Fig. 17a). Serum proteins such as albumin bind systemically delivered biological materials such as bioactive proteins, small molecule drugs and nanoparticles, and alter their biodistribution ${ }^{65}$. In addition, serum proteins are proinflammatory in neural tissue $^{19,22}$. We also evaluated the biodistribution of BDA-10 released from MP that had been loaded into $\mathrm{DCH}_{\mathrm{MO}}$. The increased non-neural and phagocyte dominated FBR associated with MP inclusion into nonionic $\mathrm{DCH}_{\mathrm{MO}}$ correlated with significantly decreased BDA-10 accumulation in neural tissue at 1 week and extensive consumption of BDA-10 by CD13-positive cells (Supplementary Fig. 18). Together, these data show that hydrogels with pronounced non-neural FBRs have reduced molecular delivery efficacy to neural tissue and that this reduction scales with the severity of the FBR. 
a
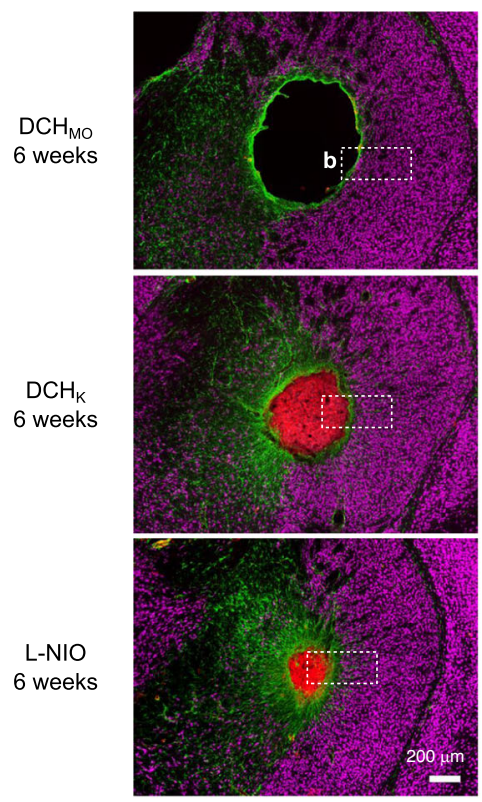

C

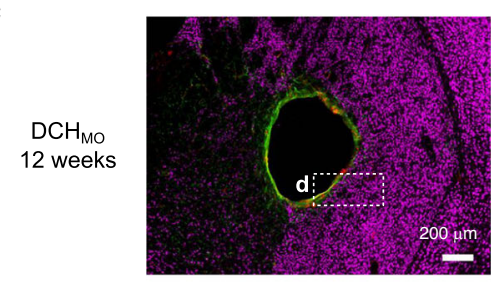

b
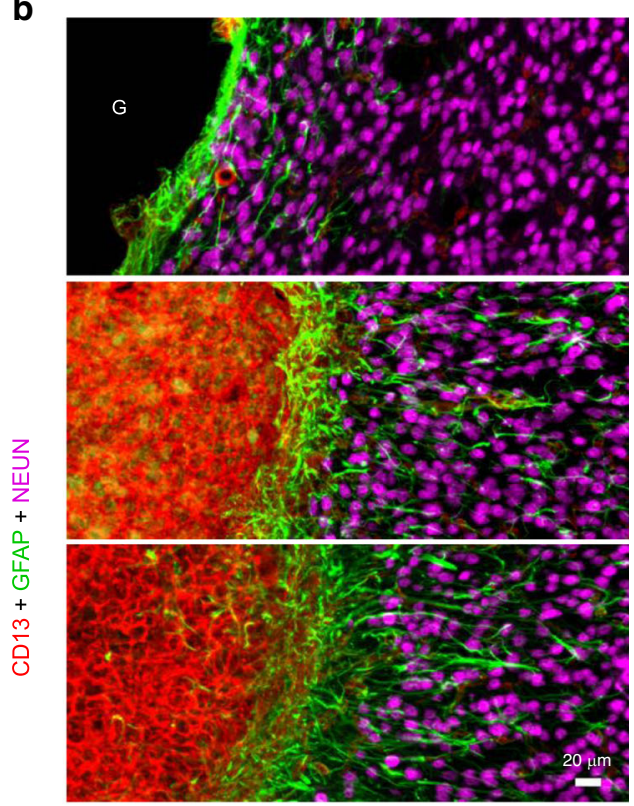

d

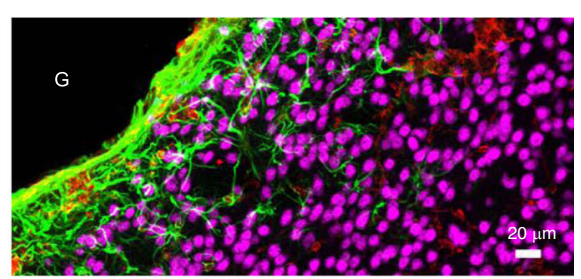

e

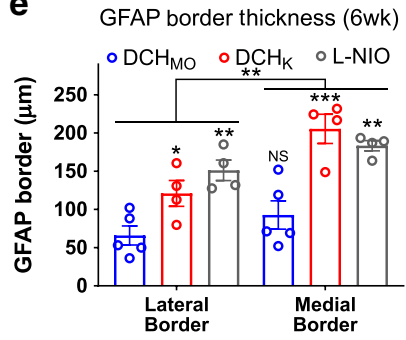

$\mathbf{f}$

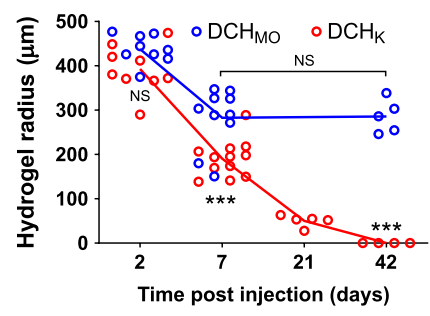

g

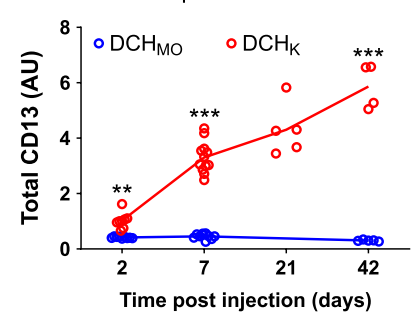

h

Microgel oligomers

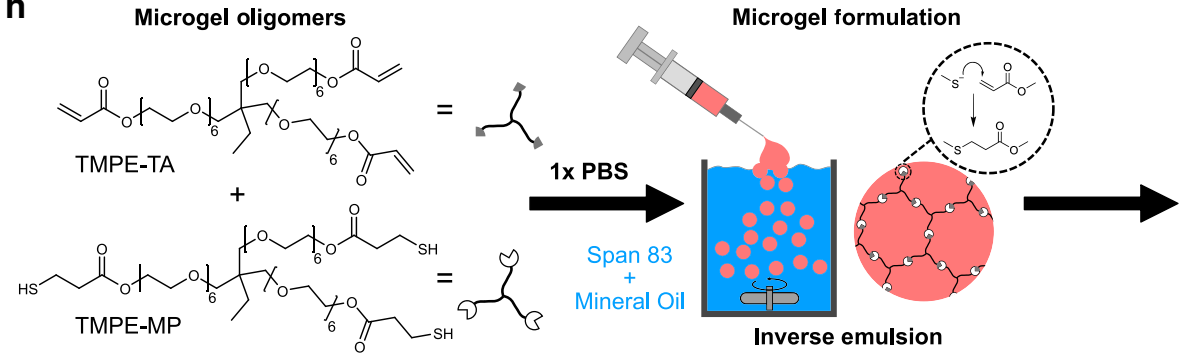

Microgel particles (MP) suspended

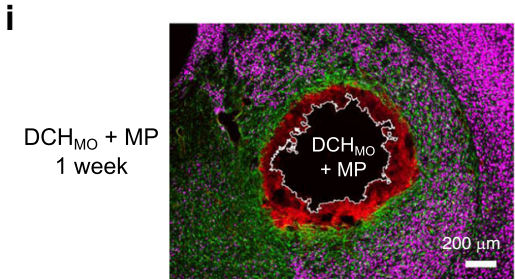

CD13 + GFAP + NEUN

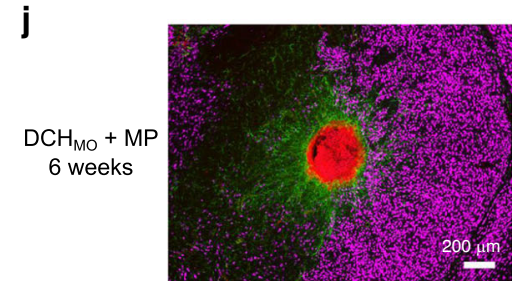

CD13 + GFAP + NEUN in physical hydrogel

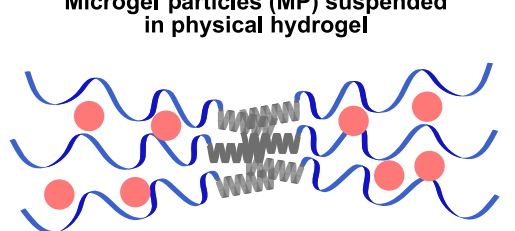

k

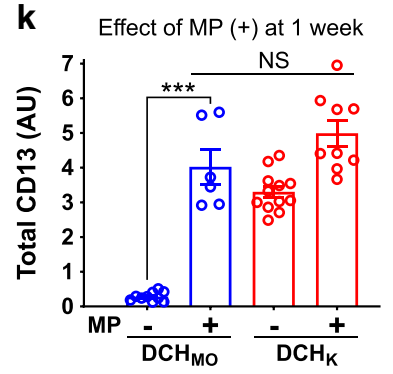

At last, we evaluated the effect of FBR on hydrogel-mediated delivery of bioactive molecules in vivo. Basal forebrain cholinergic neurons are exquisitely sensitive to nerve growth factor (NGF) levels and atrophy when deprived of NGF and hypertrophy when

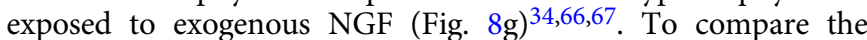
efficacy of NGF delivery by various hydrogels, we quantified the size of local striatal cholinergic neurons. NGF delivered from $\mathrm{DCH}_{\mathrm{MO}}$ and $\mathrm{DCH}_{\mathrm{K}}$ stimulated significant $40 \%$ increases in ipsilateral cholinergic neuron size relative to uninjected controls, whereas NGF delivered from $\mathrm{DCH}_{\mathrm{MM}}$ and $\mathrm{CHIT}$, which attract a severe non-neural FBR, showed highly variable effects with no overall significant increase (Fig. 8h). Incorporating data from across the molecular delivery and FBR phenotype characterizations into a principal component analysis (PCA) showed a significant inverse correlation between neural tissue molecular delivery efficacy and the severity and intensity of hydrogel FBRassociated inflammation (Fig. 8i, j, Supplementary Fig. 19).

These findings show that delivery of molecular cargo from hydrogels to CNS tissue is influenced by the nature and severity of the material-evoked FBR. In particular, an increased recruitment of peripherally derived phagocytes into hydrogel deposits results in increased consumption of cargo molecules and reduced neural tissue delivery. Further, a minimal hydrogel FBR with little or no BBB leakage results in very local delivery with a higher 
Fig. 7 Hydrogel FBR with recruited CD13-positive cells leads to hydrogel resorption. $\mathbf{a}$, $\mathbf{b}$ Survey and detail images show qualitative reductions in size of $\mathrm{DCH}_{\mathrm{K}}$ deposit and L-NIO-induced infarct, but not of $\mathrm{DCH}_{\mathrm{MO}}$ deposit at 6 weeks after injection $\mathbf{c}$, d. Survey and detail images show $\mathrm{DCH} \mathrm{H}_{\mathrm{MO}}$ deposit remains unresorbed up to 12 weeks after injection. e Quantification of GFAP-positive cell border thickness at lateral (gray matter) or medial (internal capsule)

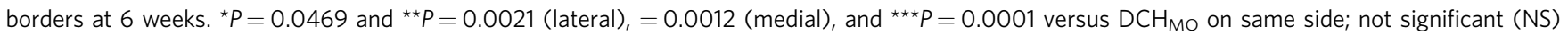
between $\mathrm{DCH}_{\mathrm{MO}}$ on either side, ${ }^{\star \star} P=0.0012$ for border location effect across all samples, two-way ANOVA with Tukey $\left(n=5,4,4\right.$ mice for DCH ${ }_{M O}$ $\mathrm{DCH}_{\mathrm{K}}$, and L-NIO, respectively). f Quantification of change in hydrogel radius for $\mathrm{DCH}_{\mathrm{MO}}$ and $\mathrm{DCH}_{\mathrm{K}}$ from 2 to 42 days. $\mathrm{NS}$, ${ }^{\star \star \star} P=0.0001$ and ${ }^{\star \star \star} P<$ 0.0001 for $\mathrm{DCH}_{K}$ versus $\mathrm{DCH}_{\mathrm{MO}}$ at 7 and 42 days, respectively; NS for $\mathrm{DCH}_{\mathrm{MO}}$ at 7 versus 42 days and for $\mathrm{DCH}_{\mathrm{MO}}$ versus $\mathrm{DCH}$ at 2 days, two-way ANOVA with Bonferroni. $g$ Quantification of change in total $\mathrm{CD} 13$ for $\mathrm{DCH}_{\mathrm{MO}}$ and $\mathrm{DCH}_{\mathrm{K}}$ from 2 to 42 days. ${ }^{\star \star} P=0.0067$ and ${ }^{\star \star \star} P<0.0001$ for $\mathrm{DCH} \mathrm{K}_{\mathrm{K}}$ versus $\mathrm{DCH}_{\mathrm{MO}}$ at the same timepoints. NS between the various timepoints for $\mathrm{DCH}_{\mathrm{MO}}$, two-way ANOVA with Bonferroni. For both $\mathbf{f}$ and $\mathbf{g}$, $n=9,10,5$ mice for $\mathrm{DCH}_{\mathrm{MO}}$ at 2, 7, and 42 days; $n=9,12,5,4$ mice for $\mathrm{DCH}_{K}$ at 2, 7, 21, 42 days. $\mathbf{h}$ Schematic of microgel particle (MP) synthesis involving inverse emulsion of polyethylene glycol (PEG)-based thiol and acrylate functionalized oligomers that react via Michael addition. MP can be readily suspended in hydrogels. $\mathbf{i}, \mathbf{j}$ Survey images of FBR to $\mathrm{DCH}_{\mathrm{MO}}$ loaded with MP at 1 week and 6 weeks show that incorporation of MP into DCH $\mathrm{H}_{\mathrm{MO}}$ leads to recruitment of $\mathrm{CD} 13$-positive cells and hydrogel resorption. $\mathbf{k}$ Quantification of effect of incorporation of $\mathrm{MP}(+)$ on total $\mathrm{CD}_{13}$-positive cell response for $\mathrm{DCH} \mathrm{H}_{\mathrm{MO}}$ and $\mathrm{DCH}_{\mathrm{K}}$ at 1 week. NS and ${ }^{\star \star \star} P<0.0001$, two-way ANOVA with Bonferroni, $n=10,6,12$, and 9 mice for $\mathrm{DCH}_{\mathrm{MO}}, \mathrm{DCH}_{\mathrm{MO}}+\mathrm{MP} \mathrm{DCH} \mathrm{H}_{\mathrm{K}}$ and $\mathrm{DCH} \mathrm{H}_{\mathrm{K}}+\mathrm{MP}_{\text {, }}$ respectively. All graphs show mean \pm s.e.m with superimposed individual data points.

proportion of targeting of cargo molecules to neurons. In contrast, more severe FBRs with pronounced BBB leakage contributes to increased dispersal of delivered molecules throughout larger volumes of neural parenchyma, and to greater targeting of those molecules to phagocytosis by microglia and perivascular cells.

FBR alters hydrogel molecular delivery and wound healing in CNS stroke injury. Injectable hydrogels are being tested extensively to deliver drugs, including growth factors, to CNS injuries. The influence of hydrogel FBRs in determining effectiveness of such treatments on neural repair outcomes remains largely uncharacterized. Unfavorable FBR effects may mask or dilute the efficacy of treatments delivered by hydrogels. To determine hydrogel FBR effects on molecular delivery to CNS injuries we injected hydrogels loaded with NGF into mouse CP at $48 \mathrm{~h}$ after initiating a large focal stroke lesion via a $2 \mu \mathrm{L}$ injection of L-NIO (Fig. 9a). We evaluated local striatal cholinergic neuron survival and size, as well as neuropil changes, as measures of NGFresponsiveness at one week after hydrogel injections into stroke lesions (Fig. 9b, c). NGF delivery from all hydrogels stimulated a significant and $\sim 50 \%$ increase in size of surviving, ipsilateral ChAT-positive neurons compared with untreated L-NIO only (Fig. 9d). NGF delivered from $\mathrm{DCH}_{\mathrm{MO}}$ but not $\mathrm{DCH}_{\mathrm{K}}$ or $\mathrm{DCH}_{\mathrm{MM}}$ also stimulated a small but significant increase in the size of contralateral ChAT-positive neurons (Fig. 9d). L-NIO stroke injury triggered a significant loss of ChAT-positive neurons in the ipsilateral striatum; and NGF delivered from $\mathrm{DCH}_{\mathrm{MO}}$, but not from $\mathrm{DCH}_{\mathrm{K}}$ or $\mathrm{DCH}_{\mathrm{MM}}$, rescued the number of ChATpositive neurons such that they were comparable to uninjured contralateral striatum (Fig. 9e). To investigate effects of NGF delivery on density of cholinergic axon networks we assessed ChAT staining intensity averaged across the neuropil. NGF delivered from $\mathrm{DCH}_{\mathrm{MO}}$ but not $\mathrm{DCH}_{\mathrm{K}}$ or $\mathrm{DCH}_{\mathrm{MM}}$ stimulated an increase in the mean ChAT intensity in the ipsilateral neuropil compared to the untreated stroke (Fig. 9f). Applying a PCA that combined all ChAT related parameters for individual animals showed a dominant $\mathrm{PC} 1$ that described $73.70 \%$ of total variation across the cohort (Fig. 9g). PC1 results for different hydrogels showed a remarkably similar hydrogel efficacy correlation to that seen for NGF delivery to uninjured healthy striatum. Animals treated with NGF using $\mathrm{DCH}_{\mathrm{MO}}$ showed the most effective NGF delivery outcomes, observed as higher positive $\mathrm{PC1}$ values (Fig. 9g). $\mathrm{DCH}_{\mathrm{K}}$ displayed significantly reduced delivery efficacy compared to $\mathrm{DCH}_{\mathrm{MO}}$ but still provided benefits over the untreated L-NIO only cohort. Delivery via $\mathrm{DCH}_{\mathrm{MM}}$ failed to significantly alter outcome compared with untreated stroke.
The natural wound healing response stimulated following stroke may be altered by hydrogel FBRs. To characterize the perturbation of the sterile inflammatory response after stroke caused by hydrogel FBRs, we used CD13 to identify non-neural cells, GFAP to define the astrocyte border and neurofilament (NFM) to demarcate neural tissue (Fig. 9h, i). In untreated strokes, distinct lesion compartmentalization was observed as described earlier with CD13-positive cells separated from NFMpositive tissue by discrete GFAP-positive astrocyte borders. Wound healing progression, defined by the distribution and total numbers of CD13-positive cells in lesion cores, was unaltered by the injection of $\mathrm{DCH}_{\mathrm{MO}}$ (Fig. 9j, k). By contrast, depots of both $\mathrm{DCH}_{\mathrm{K}}$ and $\mathrm{DCH}_{\mathrm{MM}}$ substantially modified the lesion by reducing the total number of total CD13 cells in the lesion core and stimulating a renewed increase in infiltration and persistence of CD13-negative, DAPI-positive inflammatory cells, likely neutrophils, into this tissue volume. Surrounding the nonneural lesion core, $\mathrm{DCH}_{\mathrm{MO}}$ caused no significant increase in baseline CD13 compared with the L-NIO only control. By contrast, the two cationic materials, $\mathrm{DCH}_{\mathrm{K}}$ and $\mathrm{DCH}_{\mathrm{MM}}$, stimulated significant increases in CD13-positive cell infiltrates that formed rims around the entire host interface of material deposits that persisted immediately adjacent to lesion cores at 1 week (Fig. 9l). These cationic materials also caused additional damage to ipsilateral neuropil beyond that attributed to the stroke, whereas no significant increase in neuropil loss was detected for $\mathrm{DCH}_{\mathrm{MO}}$ (Fig. 9m).

These data show that effectiveness of molecular delivery from hydrogels in stroke lesions is governed by FBR severity in a manner similar to observations in uninjured tissue. Notably, introduction into stroke lesions of hydrogels that evoked FBRs of increasing severities caused escalating destruction not only of neural tissue beyond focal lesion cores but also extensive destruction of peripherally derived cells that infiltrate into lesion cores to initiate wound healing (Fig. $9 \mathrm{~h}-\mathrm{m}$ ). This effective reinjuring of CNS lesions caused by hydrogels with severe FBRs may prolong the duration of acute inflammation, prevent reestablishment of $\mathrm{BBB}$ and leave the recipient with increased susceptibility to infection and further neural tissue damage thus potentially negating therapeutic effects derived from local molecular delivery.

\section{Discussion}

Here, we show that CNS FBRs to biomaterials mimic CNS wound responses and exist on a severity spectrum that is determined by definable chemical functionalities perceived by the host tissue at the biomaterial-tissue interface. Moreover, the nature and severity 
a

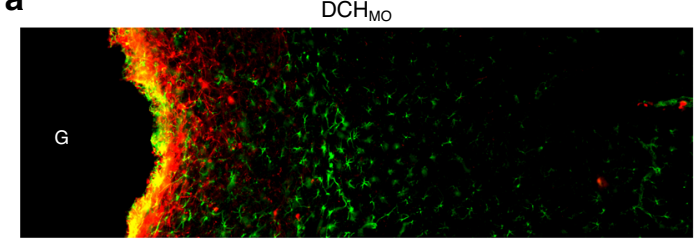

$\mathrm{DCH}_{\mathrm{K}}$

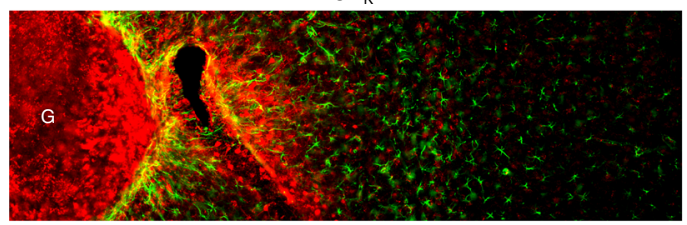

$\mathrm{DCH}_{\mathrm{MM}}$

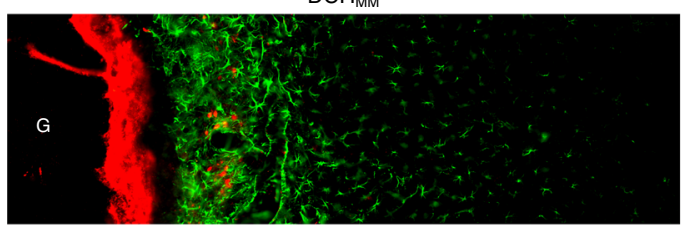

CHIT

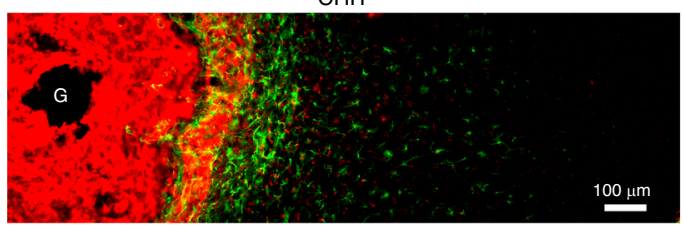

2 weeks

g

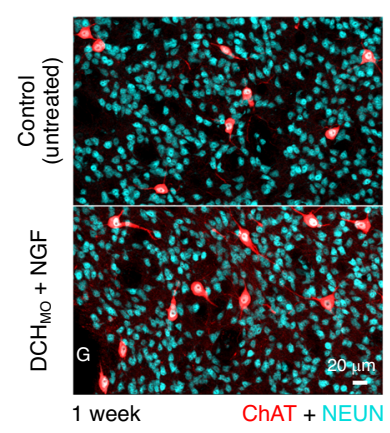

b

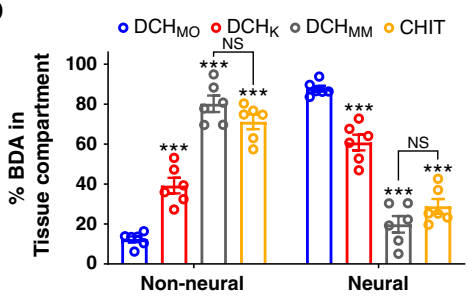

C

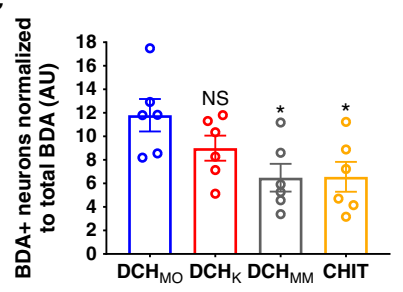

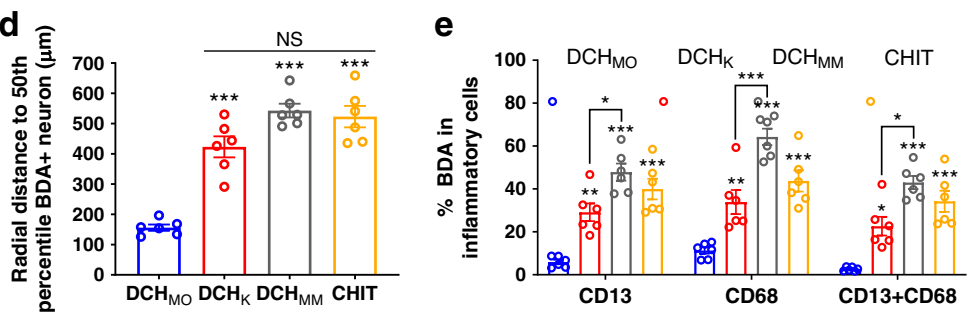

f
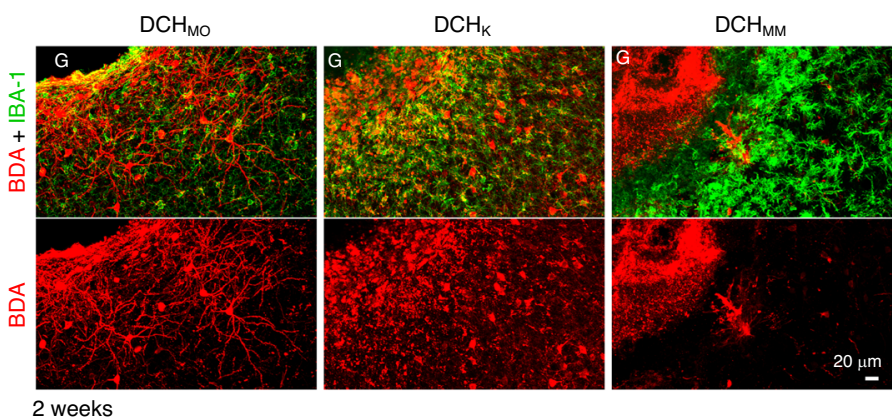

i

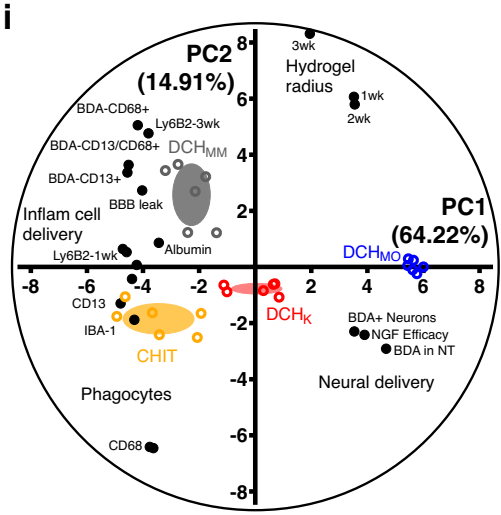

j

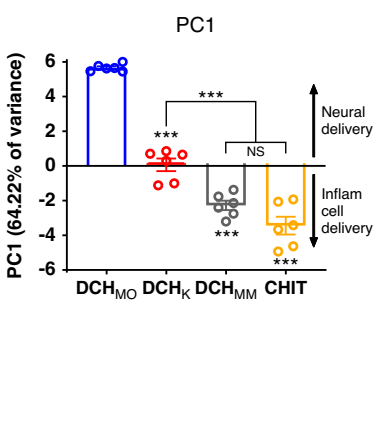

Fig. 8 Hydrogel FBR alters CNS molecular delivery. a Detail images of BDA (10 kDa) biodistribution released from DCH $\mathrm{MO}_{\mathrm{M}}, \mathrm{DCH}_{\mathrm{K}}, \mathrm{DCH} \mathrm{MM}_{\mathrm{M}}$, and $\mathrm{CHIT}$ at 2 weeks. b Quantification of BDA in tissue compartments adjacent to hydrogels. ${ }^{\star \star \star} P<0.0001$ versus $\mathrm{DCH}_{\mathrm{MO}}$; not significant (NS) for DCH $\mathrm{MM}_{\mathrm{M}}$ versus CHIT c Quantification of the normalized number of BDA-positive neurons at 2 weeks. ${ }^{\star} P=0.0375\left(\mathrm{DCH}_{\mathrm{MM}}\right)$ and $=0.0413(\mathrm{CHIT})$ and NS $\left(\mathrm{DCH} \mathrm{K}_{\mathrm{K}}\right)$ versus $\mathrm{DCH}_{\mathrm{MO}}$. d Quantification of the radial distance to the $50 \%$ percentile BDA-positive neuron from the hydrogel-tissue interface. ${ }^{\star \star \star} P<0.0001$ versus $\mathrm{DCH}_{\mathrm{MO}}$. e Quantification of BDA-positive inflammatory cells at 2 weeks. ${ }^{\star} P=0.0036,{ }^{\star \star} P=0.0005(\mathrm{CD} 13),=0.0008(\mathrm{CD} 68)$, ${ }^{\star \star \star} P<0.0001$ versus $\mathrm{DCH}_{\mathrm{MO}} \cdot{ }^{\star} P=0.0074(\mathrm{CD} 13),=0.003(\mathrm{CD} 13+\mathrm{CD} 68)$ and ${ }^{* \star *} P<0.0001$ (CD68) for $\mathrm{DCH}_{\mathrm{K}}$ versus DCH $\mathrm{MM}_{\mathrm{M}}$. For all graphs in $\mathbf{b}-\mathbf{e}, n=6$ mice per group. $\mathbf{f}$ Detail images showing phenotype of BDA-positive cells adjacent to hydrogel deposits. $\mathbf{g}$ Detail images showing increase in cholinergic (ChAT-positive) neuron size in striatum by NGF delivered from $\mathrm{DCH}_{\mathrm{MO}}$. $\mathbf{h}$ Quantification of increase in cholinergic neuron size normalized to contralateral side at 1 week

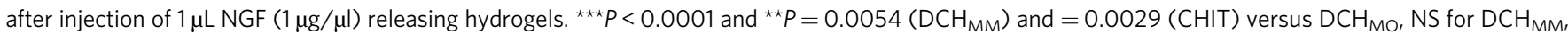
and CHIT versus untreated, ${ }^{*} P=0.0429$ for $\mathrm{DCH}_{\mathrm{MM}}$ and $=0.0233$ for $\mathrm{CHIT}$ versus $\mathrm{DCH}_{\mathrm{K}}$ respectively, NS between DCH $\mathrm{HO}_{\mathrm{M}}$ and $\mathrm{DCH} \mathrm{K}_{\mathrm{K}}(n=5,6,5,5$, and 6 mice for $\mathrm{DCH}_{\mathrm{MO}}, \mathrm{DCH}_{\mathrm{K}}, \mathrm{DCH} \mathrm{MM}_{\mathrm{M}}, \mathrm{CHIT}$, and untreated, respectively). i Principal component Analysis (PCA) for DCH $\mathrm{MO}_{\mathrm{N}} \mathrm{DCH}_{\mathrm{K}}, \mathrm{DCH} \mathrm{MM}_{\mathrm{M}}$, and $\mathrm{CHIT}$ hydrogels incorporating data from molecular delivery and immunohistochemistry evaluations. $\mathbf{j}$ Graphical representation of the positions of hydrogels along PC1 axis (accounting for $64.22 \%$ of total variance) with the positive direction representing effective neural molecular delivery while the negative direction represents molecular delivery to inflammatory cells, ${ }^{\star \star \star} P<0.0001$ for all versus $D C_{M O},{ }^{\star \star \star} P=0.0007$ for $D C H_{K}$ versus $D C H_{M M}$ and ${ }^{\star \star \star} P<0.0001$ for $\mathrm{DCH}_{\mathrm{K}}$ versus $\mathrm{CHIT}$, NS for $\mathrm{DCH}_{\mathrm{MM}}$ versus $\mathrm{CHIT}$ ( $n=6$ mice per group). For all graphs, data are mean \pm s.e.m. Statistical analysis using one (c, $\left.\mathbf{d}, \mathbf{h}, \mathbf{j}\right)$ or two-way (b, e) ANOVA with Bonferroni. 
a

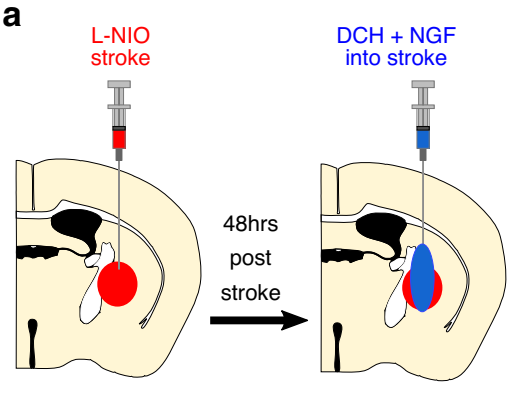

C

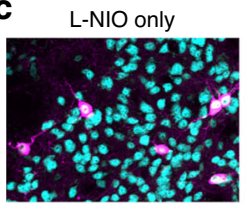

+ $\mathrm{DCH}_{\mathrm{K}} / \mathrm{NGF}$

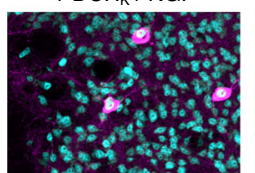

ChAT + NEUN b

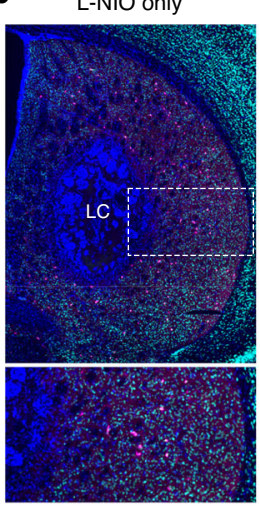

d

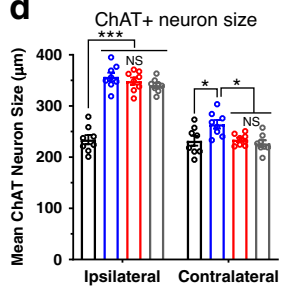

$+\mathrm{DCH}_{\mathrm{MO}} / \mathrm{NGF}$

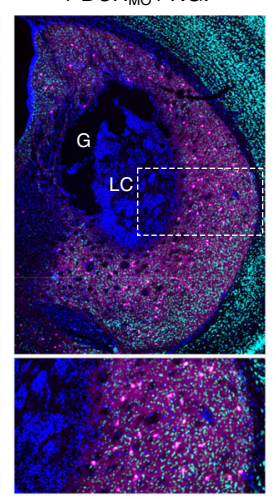

ChAT + NEUN + DAPI

e ChAT+ neuron number

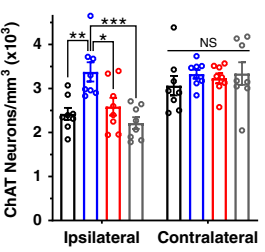

- L-NIO only $\circ+\mathrm{DCH}_{\mathrm{MO}} / \mathrm{NGF} \quad \circ+\mathrm{DCH}_{\mathrm{K}} / \mathrm{NGF}$

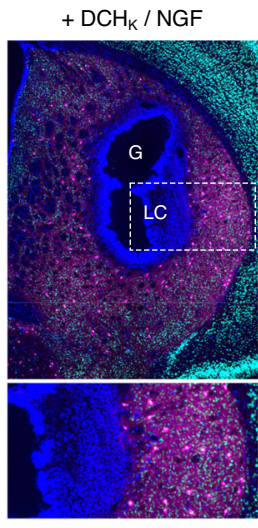

f Mean ChAT intensity

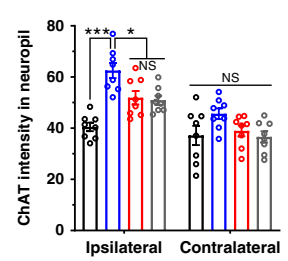

$\circ+\mathrm{DCH}_{\mathrm{MM}} / \mathrm{NGF}$

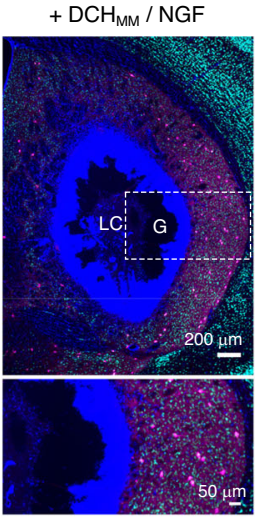

g PCA for NGF delivery effect on ChAT+ neurons

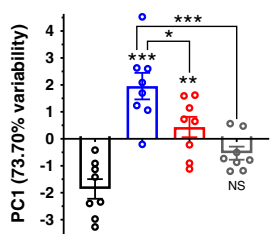

h

L-NIO only

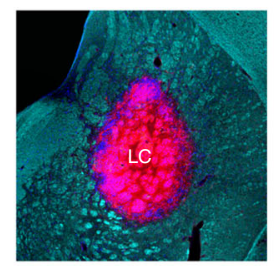

$\mathbf{j}$

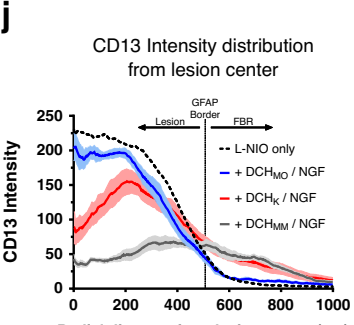

$+\mathrm{DCH}_{\mathrm{MO}} / \mathrm{NGF}$

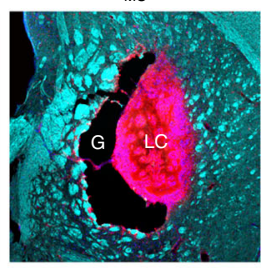

CD13 + NFM + DAP

k

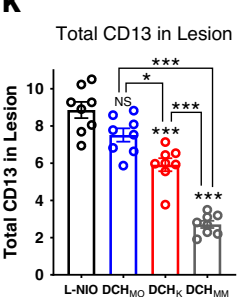

$+\mathrm{DCH}_{\mathrm{K}} / \mathrm{NGF}$

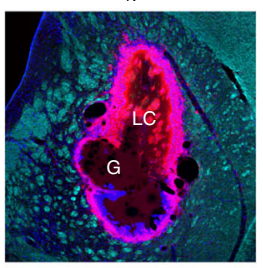

I

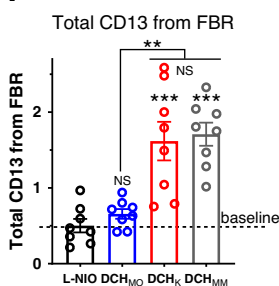

$+\mathrm{DCH}_{\mathrm{MM}} / \mathrm{NGF}$

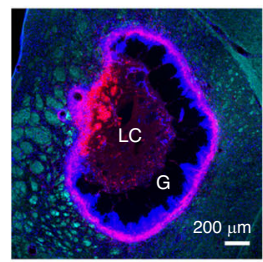

L-NIO only
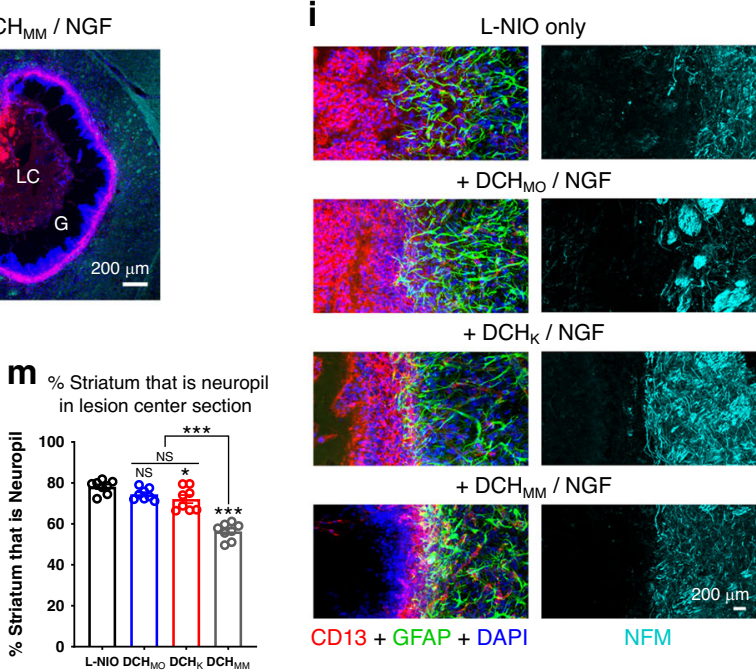

$+\mathrm{DCH}_{\mathrm{MM}} / \mathrm{NGF}$

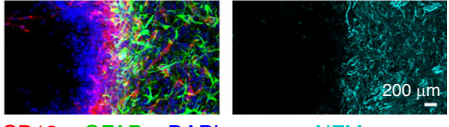

CD13 + GFAP + DAPI

NFM

Fig. 9 Hydrogel FBR alters molecular delivery of NGF and wound healing in CNS stroke injury. a Schematic summarizing experimental paradigm. b, $\mathbf{c}$ Images showing cholinergic (ChAT-positive) neurons in striatal stroke at 1 week after hydrogel (G) injection. d Quantification of mean cholinergic neuron size ipsilateral and contralateral to stroke and hydrogel injection. ${ }^{\star \star \star} P<0.0001$ for hydrogels versus L-NIO only and not significant (NS) between hydrogels ipsilaterally, ${ }^{\star} P=0.0179(\mathrm{~L}-\mathrm{NIO}),=0.0317\left(\mathrm{DCH}_{\mathrm{K}}\right)$ and $=0.004\left(\mathrm{DCH}_{\mathrm{MM}}\right)$ versus $\mathrm{DCH}_{\mathrm{MO}}$ contralaterally. e Quantification of cholinergic neuron number in striatum ipsilateral and contralateral to stroke and hydrogel injection at 1 week. ${ }^{\star} P=0.0192,{ }^{\star \star} P=0.0027,{ }^{\star \star \star} P=0.0002$ versus $D C H_{M O}$ ipsilaterally, NS between all samples in contralateral striatum. $\mathbf{f}$ Quantification of mean ChAT intensity in neuropil ipsilateral and contralateral to stroke and hydrogel injection, ${ }^{\star} P=0.0442\left(\mathrm{DCH}_{\mathrm{K}}\right),=0.0203\left(\mathrm{DCH}_{\mathrm{MM}}\right)$, ${ }^{\star \star \star} P<0.0001(\mathrm{~L}-\mathrm{NIO})$ versus $\mathrm{DCH} \mathrm{H}_{\mathrm{MO}}$ ipsilaterally, NS between all samples in contralateral striatum. g PC1 score for L-NIO only and hydrogels for PCA comparing all ChAT-neuron parameters. Positive direction represents increased ChAT responsiveness to NGF delivery, ${ }^{\star \star \star} P<0.0001,{ }^{\star \star} P=0.0011$, NS versus L-NIO only, ${ }^{\star} P=0.0404$ and ${ }^{\star \star \star} P=0.0004$ for $\mathrm{DCH}_{\mathrm{K}}$ and $\mathrm{DCH} \mathrm{M}_{\mathrm{M}}$ versus $\mathrm{DCH} \mathrm{H}_{\mathrm{MO}}$, respectively. $\mathbf{h}$, $\mathbf{i}$ Images showing altered phenotypes of CD13-positive lesion cores (LC), astrocyte border, and preserved neural tissue of striatal strokes at 1 week after hydrogel injections. j CD13-positive cell intensity plots measured radially from the center of the stroke lesion. Data are mean \pm s.e.m, with s.e.m. represented as light shaded banded areas. Location of astrocyte (GFAP) border is maximum of mean GFAP intensity plot for L-NIO only. The integral of plot to left and right of GFAP border is total CD13 in lesion and hydrogel FBR respectively. $\mathbf{k}$, I Quantification of total CD13-positive cells in lesion $\mathbf{k}$ and FBR

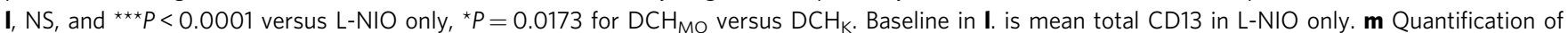
percentage neuropil remaining following stroke and hydrogel treatment in immunohistochemistry sections at center of lesion, ${ }^{\star \star \star} P<0.0001,{ }^{\star} P=0.0385$ and NS versus L-NIO only. For all graphs, data are mean \pm s.e.m. with superimposed individual data points showing $n=8$ mice per group. Statistical analysis using one $(\mathbf{g}, \mathbf{k}, \mathbf{I}, \mathbf{m})$ or two-way $\mathbf{d}-\mathbf{f}$ ANOVA with Bonferroni. 
of FBRs significantly affect multiple aspects of biomaterial function when applied to both healthy and ischemic stroke injured neural tissue. These findings have broad implications for developing, testing, and using biomaterials for CNS applications, and also for understanding the conserved biology of the CNS wound response and astroglial limitans border formation. We provide a framework for comprehensively evaluating in vivo responses to biomaterials for CNS applications, which may facilitate the development and characterization of new and improved systems.

As a platform to study CNS FBRs evoked by definable chemical functionalities presented to host cells by biomaterials, we used readily modified synthetic hydrogels whose direct interfaces with host cells can sensitively and intimately be evaluated in vivo. Our findings show that specific physiochemical properties presented at biomaterial-host interfaces, such as cationic, nonionic, or anionic interfaces with CNS cells, evoke quantifiably different FBR phenotypes with respect to levels of stromal cell infiltration, inflammation, tissue fibrosis, astroglial border formation, and $\mathrm{BBB}$ disruption. Moreover, we show that FBRs evoked by materials in CNS are directly related to, and mimic, the multicellular CNS wound response to tissue injury (modeled here by the response to an ischemic infarct), and are best understood in the context of this conserved biology. Trauma, ischemia, autoimmune attack and infections all generate potentially toxic cellular debris that trigger multicellular wound responses as naturally occurring events. The conserved CNS wound response serves to recruit inflammatory cells that degrade toxic elements and also simultaneously serves to isolate damaged tissue, debris, and inflammation from adjacent viable neural tissue and to restore barrier functions important for normal CNS function ${ }^{19,22,55}$. In this manner, naturally occurring CNS wound responses give rise to discrete lesion compartments with central cores of non-neural tissue surrounded by astrocyte limitans borders that are continuous with spared and reorganizing neural tissue. This compartmentalized organization is mimicked by FBRs evoked by biomaterials (Fig. 10). This specialized multicellular and compartmentalized CNS wound response or FBR is not present in peripheral tissues, and thus evaluation of biomaterial FBR in peripheral tissue alone is not sufficient to predict performance in the CNS. Naturally occurring CNS wound responses exist on a severity spectrum that varies with: (i) the degree of the tissue damage, (ii) the nature and the toxicity of debris, and (iii) the presence or absence of microbes or their associated signals. Similarly, the nature and severity of FBRs to biomaterials vary with the molecular features of the interface presented to host tissue.

The phenotypic differences in FBRs for different hydrogels mimic the diversity of functional barriers that are established in various healthy and disease states in the CNS (Fig. 10). FBRs evoked by nonionic and anionic interfaces, such as seen for $\mathrm{DCH}_{\mathrm{MO}}$, are minimal and appear morphologically similar to healthy glia limitans borders that exist at natural edges of healthy CNS tissue such as the meninges. These discrete glia limitans borders are formed at the new discontinuity in neural tissue that is created as a result of the injection of these material into healthy neuropil. Using dynamic and biologically conserved processes, CNS glia form borders around all entities detected as being of "non-neural" origin, including stromal cells, microbial organisms or biomaterials. Therefore, neural integration with biomaterial constructs, even those displaying a minimal FBR, will require identifying strategies to regulate or disrupt the processes by which glia recognize the need to form these borders. FBRs to cationic materials, such as $\mathrm{DCH}_{\mathrm{K}}$, that attract and allow resorption by innate-immune cells, exhibit the most striking similarity to stroke lesions. As the focal injury zone created by these materials is less diffuse than stroke lesions and isolated to only a few cell layers adjacent to the material interface, these materials may provide a useful tool for evaluating the biology of cellular processes involved in CNS injury lesion border formation. In contrast, another cationic material, $\mathrm{DCH}_{\mathrm{MM}}$, which is incapable of being resorbed by innate-immune cells due to frustrated phagocytosis, displays characteristic concentric inflammatory cell layers that are phenotypically similar to chronic granuloma caused for example by mycobacterial infections. This material may prove a useful tool for studying granuloma pathophysiology. The spectrum of biomaterial FBRs identified in this study mimic various aspects of CNS pathology and may each individually prove to be useful tools to controllably elucidate, and thus further dissect, the cellular mechanisms involved in natural host responses to CNS injury and disease.

Our findings also emphasize the need for use of multiple markers to assess multiple FBR dimensions, including markers of stromal, inflammatory and multiple glial cells, as well as markers of neural tissue damage and fibrosis. We show that GFAP, a commonly used marker of astrocyte reactivity that can indicate tissue pathology ${ }^{19}$, is on its own not a sufficient or reliable marker to evaluate and differentiate material or device FBRs. For example, we show that total GFAP levels are essentially indistinguishable in neural tissue within close proximity to biomaterials that evoke markedly different FBR severities, including FBRs that evoke pronounced levels of inflammation and fibrosis that impact significantly on function. Our findings provide a framework of multiple molecular markers and experimental tools for comprehensive evaluation of material FBRs in the CNS in vivo using readily available immunohistochemical reagents that can be applied to benchmark the performance of new biomaterial formulations against various well characterized formulations used here. Future work to extend the FBR evaluation framework could include dynamic physiological evaluations of neurons and glia in the preserved neuropil adjacent to biomaterial FBRs by incorporating emerging neurobiology techniques such as non-invasive in vivo imaging of single wavelength molecular sensors ${ }^{68,69}$.

We also show that the nature and severity of FBRs strongly influence biomaterial function in the CNS as studied here in the form of rate of hydrogel resorption, biodistribution of molecular cargo delivery to neural parenchyma and efficacy of bioactive molecular delivery. Thus, developing hydrogels and other biomaterials with efficient functions for CNS applications will require a detailed understanding of their in vivo FBRs. In vitro evaluations of molecular release dynamics are on their own insufficient to predict efficacy of molecular delivery in the CNS in vivo, because delivery will be strongly influenced by CNSspecific FBRs. For example, we show that MPs that significantly extend molecular release duration from hydrogels in vitro can attract phagocytes in vivo that significantly reduce molecular delivery compared with the hydrogels they are suspended in. Notably, our findings indicate that hydrogel formulations with features that attract phagocytic cells such as blood-borne macrophages and neutrophils will have particularly poor functional performance in molecular delivery to host tissue (and most likely also as vehicles for cell grafts). Moreover, we show that these hydrogel features may not be revealed by solely examining the glial response of more distant surrounding neural tissue, because hydrogel deposits are rapidly and effectively isolated as part of the FBR, which mimics naturally occurring wound responses that maximize the protection of adjacent neural tissue ${ }^{19,22}$. This study further demonstrated that materials that elicited severe FBRs when applied to healthy, uninjured brain lead to worse bioactive molecular delivery and impeded natural wound repair processes when applied to stroke lesions. Therefore, evaluating biomaterial FBRs in uninjured, healthy CNS represents important and 
a

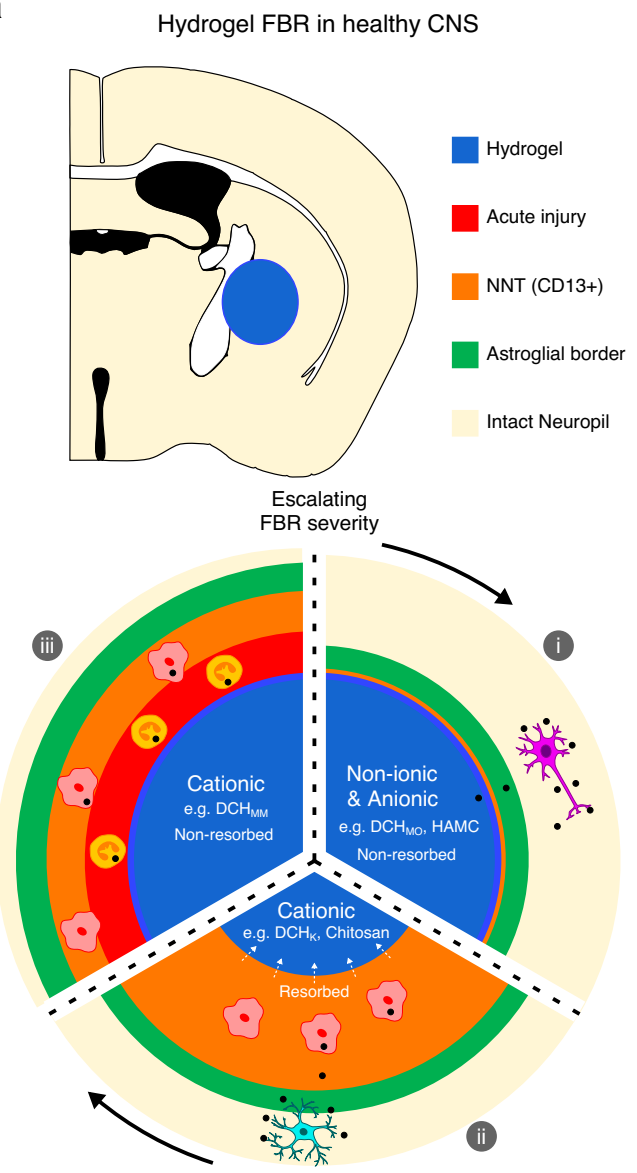

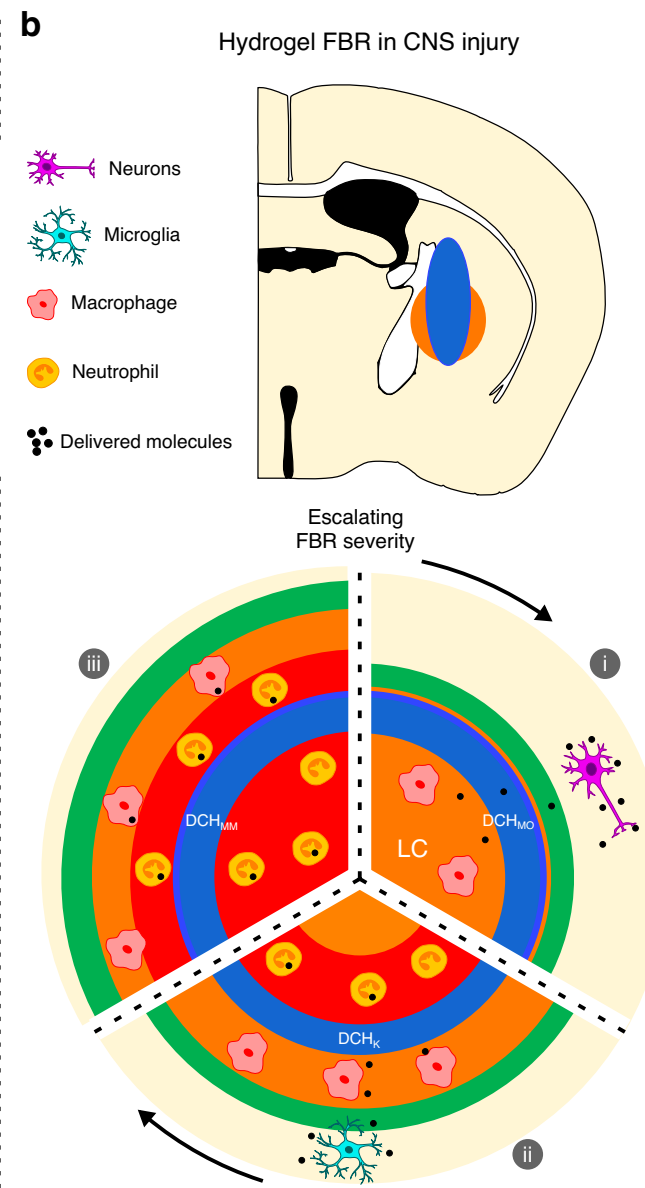

Fig. 10 Schematic summarizing the main findings of this study. a FBRs to hydrogels injected into healthy uninjured CNS mimic natural wound healing responses to CNS tissue injury and exist on a severity spectrum that is dependent on definable material properties. This study identified that hydrogel chemistry presented to the host at the biomaterial-tissue interface determines FBRs and that CNS FBR phenotype and its severity alters hydrogel function in terms of molecular delivery and biomaterial resorption. (i) Non-ionic and anionic hydrogels demonstrated: minimal peripheral derived inflammation, minimal fibrosis, limited resorption, and enhanced molecular delivery to neurons. Cationic hydrogels provoke significant non-neural tissue (NNT) FBRs resulting in predominant inflammatory cell delivery as well as either rapid resorption (ii), or frustrated phagocytosis and persistent acute inflammation and limited resorption (iii). b FBRs to hydrogels injected into subacute CNS stroke injuries influenced molecular delivery to preserved neurons and altered CNS wound healing processes. When applied to striatal stroke, nonionic hydrogels $\left[\mathrm{DCH}_{\mathrm{MO}}-(\mathrm{i})\right]$ showed improved bioactive molecular delivery to neurons without significantly altering the stroke lesion core (LC). Cationic materials $\left[\mathrm{DCH}_{\mathrm{K}}\right.$-(ii) and $\mathrm{DCH}_{\mathrm{MM}}-$ (iii) $]$ showed reduced molecular delivery efficacy and disruption of natural wound healing processes within LCs.

necessary in vivo investigations for any new material prior to consideration for use to deliver experimental therapies to preclinical CNS injury models.

In this study, we used hydrogels as surrogate biomaterials to characterize host responses to specifically presented chemical functionalities, and molecular delivery from hydrogels was the primary functional outcome measure evaluated. The basic principles we identified can inform the development of materials for a variety of CNS applications including implantable neuroprostheses for recording and stimulating neural circuit activity $2,3,23,70$. For example, we show that surface charge at the material-host interface influences the severity of FBRs, which in turn will influence the degree of protective fibrotic and astrocyte barrier formation, which serves to isolate the materials from adjacent neural tissue and may thereby attenuate function. Thus, such devices will also benefit from detailed characterization of FBRs as described here. Although the bulk of implantable neuroprostheses most frequently employed in human and nonhuman primate studies currently make use of non-resorbable, hydrophobic polymers that may stimulate unique FBR phenotypes in addition to that described here ${ }^{23}$, emerging systems are opting for hydrophilic, hydrogel-based coatings/substrates with comparable chemistries to this study ${ }^{71,72}$. Thus, it would seem particularly appropriate to apply the FBR evaluation framework outlined here to these new formulations as part of preclinical testing protocols moving forward. Furthermore, incorporating the identified hydrogel chemical functionalities that evoked minimal FBRs (e.g., methionine sulfoxide functional groups from $\mathrm{DCH}_{\mathrm{MO}}$ ) into future neural electrode design may be a useful strategy in attenuating the thickness of disrupted tissue and the intensity of the astroglial border-forming response between the device and viable neural tissue.

Our findings also inform the understanding of CNS wound responses by demonstrating and characterizing how FBRs fall firmly within the framework of the conserved multicellular biology of such responses. In this regard, we also add to the growing evidence $^{48-53}$ that APP accumulation and the acute formation of A $\beta$ are consequent responses to neural tissue injury that occur in direct proportion to the level of neuronal and axonal damage, and are thus part of the conserved biology of CNS wound responses and FBRs.

In conclusion, we show that material FBRs are determined by definable properties presented at host interfaces, which can be 
modified to minimize or evoke specific responses. Understanding these properties and the CNS-specific FBRs that they evoke in vivo will be critical to designing new materials for diverse CNS applications. In addition, this observation raises the intriguing prospect of engineering biomaterials with originally inert profiles, which can then be modified to present specific molecular features in order to dissect cell surface and contact-mediated molecular mechanisms that drive specific elements of naturally occurring CNS wound responses.

\section{Methods}

Animals. All in vivo experiments involving the use of mice were conducted according to protocols approved by the Animal Research Committee (ARC) of the Office for Protection of Research Subjects at University of California Los Angeles (UCLA). All in vivo animal experiments were conducted within approved UCLA facilities using wildtype or transgenic C57/BL6 female and male mice that were aged between 8 weeks and 4 months old at the time of craniotomy surgery. Transgenic td-Tomato (tdT) reporter mice were bred with inducible Cre lines to identify Astrocytes (Aldh1L1-Cre-ERT2) and NG2 cells (NG2-Cre-ERT2). Transgenic mice (aged between 6 and 12 weeks) were administered tamoxifen to induce Cre expression. Tamoxifen in corn oil at a concentration of $20 \mathrm{mg} / \mathrm{ml}$ was administered via intraperitoneal (IP) injection for 5 days at a dose of $50 \mathrm{mg} / \mathrm{kg}$ per day. Following the last dose of tamoxifen, mice were kept for 3 weeks before undergoing surgery for hydrogel injection to allow residue tamoxifen to clear out of the mouse's system. Mice were housed in a 12-hour light/dark cycle in a specific pathogen-free facility with controlled temperature (maintained within range of $20-26^{\circ} \mathrm{C}$ ) and humidity (maintained within range of $30-70 \%$ ) and were provided with food and water ad libitum.

Surgical procedures for mice. All surgical procedures were approved by the UCLA ARC and conducted within a designated surgical facility at UCLA. Hydrogel brain injections were performed on mice under general anesthesia achieved through inhalation of isoflurane in oxygen-enriched air. Prior to incision, the mouse head was stabilized and horizontally leveled in a rodent stereotaxic apparatus using ear bars (David Kopf, Tujunga, CA). A small craniotomy was performed using a high speed surgical drill and visually aided by an operating microscope (Zeiss, Oberkochen, Germany). Hydrogel injections were made in the brain using pulled borosilicate glass micropipettes (WPI, Sarasota, FL, \#1B100-4) that were ground to a $35^{\circ}$ beveled tip with $150-250 \mu \mathrm{m}$ inner diameter. Glass micropipettes were mounted to the stereotaxic frame via specialized connectors and attached, via high-pressure polyetheretherketone tubing, to a $10 \mu \mathrm{L}$ syringe (Hamilton, Reno, NV, \#801 RN) that was controlled by an automated syringe pump (Pump 11 Elite, Harvard Apparatus, Holliston, MA). Each hydrogel was backloaded into the micropipette prior to connecting to the stereotaxic frame. A volume of $1 \mu \mathrm{L}$ of hydrogel was injected into the $\mathrm{CP}$ nucleus at $0.15 \mu \mathrm{L} / \mathrm{min}$ using target coordinates relative to Bregma: $+0.5 \mathrm{~mm} \mathrm{~A} / \mathrm{P},+2.5 \mathrm{~mm} \mathrm{~L} / \mathrm{M}$ and $-3.0 \mathrm{~mm}$ $\mathrm{D} / \mathrm{V}$. For the NGF delivery studies target coordinates relative to Bregma: $+1 \mathrm{~mm}$ $\mathrm{A} / \mathrm{P},+2.2 \mathrm{~mm} \mathrm{~L} / \mathrm{M}$, and $-3.0 \mathrm{~mm} \mathrm{D} / \mathrm{V}$ were used. The micropipette was allowed to dwell in the brain at the injection site for an additional $4 \mathrm{~min}$ at completion of hydrogel injection. The micropipette was then removed from the brain slowly and incrementally over a $2 \mathrm{~min}$ period. After removal of the micropipette, the craniotomy window was left unaltered while the incision site was sutured closed. Animals were allowed to recover on a warm heating pad for 48 hours after surgery with post-surgical buprenorphine $(0.1 \mathrm{mg} / \mathrm{kg})$ given every $12 \mathrm{~h}$ during this period. To create focal ischemic strokes, $1 \mu \mathrm{L}$ of L-NIO (N5-(1-Iminoethyl)-L-ornithine) solution was injected into CP nucleus of the striatum using the same micropipette injection protocol as above. The L-NIO solution was prepared by solubilizing lyophilized L-NIO powder (Cat. No. 0546, Tocris) in sterile $1 \times$ PBS at a concentration of $27.4 \mathrm{mg} / \mathrm{ml}(130 \mu \mathrm{M})$. To create forebrain stab injuries, a 16 Gauge 1" hypodermic needle was mounted to the stereotaxic frame and slowly lowered into mouse brain at the same target coordinates outlined above. The needle was allowed to dwell at the target coordinate location for $4 \mathrm{~min}$ and removed slowly thereafter.

To investigate hydrogel FBRs in the context of CNS injury, two separate surgeries were performed. Firstly, to create large focal ischemic strokes $2 \mu \mathrm{L}$ of LNIO solution was injected into CP nucleus of the striatum using the methods described above. The animals were allowed to recover for $48 \mathrm{~h}$ before undergoing a second surgery where $1 \mu \mathrm{L}$ of DCH loaded with NGF (see specific formulation details below) was injected into the same stereotactic location as the stroke lesion using the same methods described above. After hydrogel injection the surgical incision site was sutured closed and the animals were allowed to recover before being transcardially perfused at 1 week after hydrogel injection.

Synthesis and formulation of hydrogels. Physically crosslinked hydrogels were formulated from polypeptide or polysaccharide polymers (Fig. 1a, Supplementary Fig. $3 a, b)$ that were synthesized using procedures developed previously by our group or purchased from commercial sources and used as received.
Preparation of diblock copolypeptide hydrogels (DCH): The polypeptides were prepared using synthetic schemes reported previously. Specific and detailed synthetic protocols for preparing $\mathrm{DCH}_{\mathrm{MO}}, \mathrm{DCH}_{\mathrm{K}}, \mathrm{DCH}_{\mathrm{MM}}, \mathrm{DCH}_{\mathrm{E}}, \mathrm{DCH}_{\mathrm{MOK} 10}$, $\mathrm{DCH}_{\mathrm{MOE} 15}$ have been provided across a number of previous peer reviewed publications $8,25,34$.

$\mathrm{DCH}_{\mathrm{MOE} 15}$ was prepared for the first time as part of this current work and the method for synthesizing this polypeptide can serve as a general overview for polypeptide synthesis. Polypeptide synthesis was performed in a $\mathrm{N}_{2}$ filled glove box using anhydrous solvents. Amino acid N-carboxyanhydride (NCA) monomers including tert-butyl-L-glutamate NCA, L-methionine NCA, L-leucine NCA were prepared by phosgenation of a tetrahydrofuran (THF) solution of the corresponding amino acid in a Schlenk flask under $\mathrm{N}_{2}$ and purified by either recrystallization or column chromatography as outlined before. To prepare copolypeptides at ca. $100 \mathrm{mg}$ scale, a solution of initiator, $\mathrm{Co}\left(\mathrm{PMe}_{3}\right)_{4},(3.5 \mathrm{mg}$, $0.001 \mathrm{mmol})$ in THF $(20 \mathrm{mg} / \mathrm{mL})$ was quickly added to a mixture of L-methionine NCA (Met NCA; $100 \mathrm{mg}, 0.57 \mathrm{mmol}$ ) and tert-butyl-L-glutamate NCA (tert-butyl Glu NCA; $23 \mathrm{mg}, 0.10 \mathrm{mmol})$ in THF $(50 \mathrm{mg} / \mathrm{mL})$. After $2 \mathrm{~h}$, complete consumption of NCA was confirmed by Fourier transform infrared (FTIR) spectroscopy. In order to determine the lengths of poly(L-methionine-stat-tertbutyl-L-glutamate $)_{\mathrm{m}},\left(\mathrm{ME}^{\mathrm{tB}}\right) \mathrm{m}$, segments, a small aliquot $(200 \mu \mathrm{l})$ of polymerization mixture was removed, reacted with $\alpha$-methoxy- $\omega$-isocyanoethylpoly(ethylene glycol $)_{45}\left(\mathrm{mPEG}_{23}-\mathrm{NCO}\right)$ and chain length determined by end-group analysis using ${ }^{1} \mathrm{H}$ NMR. To the remaining copolymerization mixture L-leucine NCA (Leu NCA; $14 \mathrm{mg}, 0.088 \mathrm{mmol}$ ) in THF $(50 \mathrm{mg} / \mathrm{mL}$ ) was then added. The Leu NCA monomers were found to be completely consumed within $\sim 1 \mathrm{~h}$, and the reaction mixture was subsequently removed from the glove box. The block copolypeptide solution was then precipitated by addition to a DI water solution $(75 \mathrm{~mL})$, filtered, washed with DI water, and dried under reduced pressure to obtain a white fluffy solid ( $91 \mathrm{mg}, 95 \%$ yield).

The deprotection of tert-butyl-L-glutamate residues was performed before the oxidation of $\mathrm{L}$-methionine residues. To facilitate deprotection, $\left(\mathrm{ME}^{\mathrm{tB}}\right)_{170} \mathrm{~L}_{24}(\mathrm{ca} .80$ $\mathrm{mg}$ ) was fully dissolved in trifluoroacetic acid (ca. $25 \mathrm{mg} / \mathrm{mL}$ ) and stirred at ambient temperature for $16 \mathrm{~h}$. The copolypeptide was then precipitated into diethyl ether $(75 \mathrm{~mL})$. The diethyl ether was decanted and the copolypeptide was dried under reduced pressure overnight to yield a white solid ( $c a .74 \mathrm{~g}, 99 \%$ yield, $97 \%$ deprotection efficiency). To convert L-methionine residues in copolypeptides to Lmethionine sulfoxide residues, a volume of $70 \mathrm{wt} \%$ tert-butyl hydroperoxide (16 molar equivalents per L-methionine residue) was added to a sample of solid copolypeptide (ca. $80 \mathrm{mg}$ ). The reaction mixture was then diluted with DI water to yield an overall polypeptide concentration of $20 \mathrm{mg} / \mathrm{mL}$. To aid oxidation, a catalytic amount of camphorsulfonic acid ( 0.2 molar equivalents per Met residue) solution in DI water $(20 \mathrm{mg} / \mathrm{ml})$ was subsequently added. The reaction mixture was stirred vigorously for $24 \mathrm{~h}$ at ambient temperature, whereupon complete dissolution of the copolypeptide sample was observed. Reaction mixtures were transferred to 2000 MWCO dialysis bags and dialyzed against: (i) pyrogen-free deionized milli-Q water $(3.5 \mathrm{~L})$ containing sodium thiosulfate $(1.2 \mathrm{~g}, 2.2 \mathrm{mM})$ for 1 day to neutralize residual peroxide, (ii) pyrogen-free deionized milli-Q water (3.5 L) containing ethylenediaminetetraacetic acid tetrasodium salt hydrate $(1.0 \mathrm{~g}, 2.63$ $\mathrm{mmol}$ ) to aid cobalt ion removal, (iii) pyrogen-free deionized milli-Q water $(3.5 \mathrm{~L}$ ), which was adjusted to $\mathrm{pH} 8$ with $1.0 \mathrm{M} \mathrm{NaOH}$ and contained sodium chloride $(5 \mathrm{~g}$, $85.5 \mathrm{mmol}$ ) for 2 days to aid in counter ion exchange of glutamate residues, and (IV) pyrogen-free deionized milli-Q water (3.5 L) for 2 days to remove residual ions. For each step dialysate was changed every $12 \mathrm{~h}$. The copolypeptide solution was then freeze dried to yield a white fluffy solid (ca. $85 \mathrm{~g}, 95 \%$ yield, and $100 \%$ conversion of L-methionine residues in copolypeptides to L-methionine sulfoxide groups).

All DCH variants were prepared by solubilizing lyophilized copolypeptide in PBS and leaving to assemble for $24 \mathrm{~h}$, without stirring, before use. All DCH formulations were prepared at $4.0 \mathrm{wt} \%$ in PBS. All polymer chemical structures were prepared using ChemDraw 18.2.

Preparation of polysaccharide-based hydrogels: Polysaccharide-based hydrogels of chitosan, methylcellulose (MC) and HAMC were prepared following procedures detailed in the literature. To formulate chitosan hydrogels, solutions of chitosan $[\mathrm{MW}=50,000-190,000 \mathrm{Da}$; DDA $\approx 85 \%]$ (Sigma, \#448869) in $0.1 \mathrm{M}$ acetic acid were prepared at $2.3 \%(\mathrm{w} / \mathrm{v})$ and allowed to dissolve overnight at $4{ }^{\circ} \mathrm{C}^{33}$. A $50 \% \mathrm{w} / \mathrm{v}$ or 2.314 M solution of $\beta$-glycerophosphate disodium salt (Sigma, \#G9422) in water was subsequently added dropwise to the chitosan solution on ice and manually stirred to form a uniform solution and elevate the solution $\mathrm{pH}$ to 7.4. Prior to surgical micropipette loading, the chitosan hydrogel was incubated at $37^{\circ} \mathrm{C}$ for 1 hour to initiate physical gelation. MC (Methocel A15C, $[\mathrm{MW}=304 \mathrm{kDa}$; 27.5-31.5\% substitution], Sigma \#64625) hydrogels were prepared by dispersing and then solubilizing at $4{ }^{\circ} \mathrm{C}$ at a concentration of $4 \mathrm{wt} \%{ }^{31}$. The HAMC hydroge was prepared by dispersing a measured amount of hyaluronic acid [1.01-1.8 MDa] (Lifecore Biomedical, \#HA15M-1) into a pre-dissolved $4 \mathrm{wt} \% \mathrm{MC}$ solution and allowed to dissolve at $4{ }^{\circ} \mathrm{C}$ overnight. The HAMC blended hydrogel used for in vivo studies had a concentration of $1 \% \mathrm{HA}$ and $3 \% \mathrm{MC}$, which was equivalent that used previously within in vivo CNS studies ${ }^{32}$.

For BDA delivery experiments, appropriate volumes of $10 \% \mathrm{w} / \mathrm{v}$ stock solutions of BDA (10 kDa-Thermofisher, \#D1956 or $70 \mathrm{kDa}-$ Thermofisher, \# D1957) in PBS were added to the polymer solutions to net a final concentration of $1 \%$ BDA in hydrogels. For NGF delivery experiments, lyophilized recombinant human $\beta$-NGF 
(PeproTech, Cat\# 450-01, Rocky Hill, NJ) was reconstituted in PBS and added to the polymers to form hydrogels with a final concentration of NGF of $1 \mathrm{mg} / \mathrm{mL}$.

Microgel MP synthesis. MPs based on PEG microgels were derived by covalently reacting ethoxylated trimethylolpropane oligomers functionalized with either acrylate or thiol acid ester groups under physiologically buffered conditions by thiol-ene Michael Addition as reported before ${ }^{58}$. A standard inverse emulsion technique was applied to formulate microgels whereby aqueous buffer solubilized oligomers were dispersed in a larger volume mineral oil bath that contained the nonionic sorbitan alkyl ester surfactant, Span 83 , to create a stable emulsion and direct microgel size ${ }^{59,60}$. The emulsion was stirred for one hour at room temperature on a magnetic stir plate before being washed and centrifuged three times with hexanes to remove the mineral oil and surfactant. Collected MPs were dried under high vacuum to evaporate residual hexane solvent. Microgels were uniformly dispersed in PBS at $6 \mathrm{wt} \%$ using a pellet pestle mixer and added to hydrogel solutions to a final concentration of $3 \mathrm{wt} \%$. For BDA delivery experiments, appropriate volumes of $10 \%$ BDA- 10 stock were added to the aqueous reaction buffer during microgel synthesis to load microgel particles with BDA.

\section{Hydrogel and microparticle characterization. Dynamic mechanical rheology:} dynamic rheological measurements were performed at constant set temperature of $25^{\circ} \mathrm{C}$ using a Physica MCR 301 (Anton Paar, Sweden) equipped with a $25 \mathrm{~mm} 1^{\circ}$ cone and plate geometry. To determine the linear viscoelastic testing region for each DCH sample a frequency sweep from 0.1 to $100 \mathrm{rad} \mathrm{s}^{-1}$ at a fixed strain of $0.5 \%$ was applied followed by a strain sweep from 0.1 to $100 \%$ strain at a fixed frequency of $10 \mathrm{rad} \mathrm{s}^{-1}$. DCH samples were allowed to recover for a period of 2 min between individual rheological experiments. To compare mechanical properties across various DCH samples a time sweep under fixed strain and frequency conditions $\left(0.5 \%\right.$ strain and $\left.10 \mathrm{rad} \mathrm{s}^{-1}\right)$ was applied for one minute.

Zeta potential measurement: $\mathrm{K}_{170}$ (hydrophilic block of $\left.\mathrm{DCH}_{\mathrm{K}}\right),\left(\mathrm{M}^{\mathrm{O}} \mathrm{A}\right)_{170}$ (hydrophilic block of $\mathrm{DCH}_{\mathrm{MO}}$ ), and $\left(\mathrm{M}^{\mathrm{M}} \mathrm{A}\right)_{170}$ (hydrophilic block of $\mathrm{DCH}_{\mathrm{MM}}$ ), were dissolved at $15 \mathrm{mg} / \mathrm{mL}$ in a $20 \mathrm{mM}$ phosphate buffer solution at $\mathrm{pH} 7.4$, which was filtered through a $0.45 \mu \mathrm{m}$ membrane syringe filter. Mean zeta potentials were analyzed using a Zetasizer NanoZS instrument (Malvern Instruments Ltd., United Kingdom). Samples were analyzed in monomodal mode where fast field reversal technique was applied and the electrophoretic mobility was calculated using the Henry equation. Sample were prepared in triplicate and analyzed three times.

FTIR: dried MPs were analyzed by FTIR to confirm the presence of the crosslinked ethoxylated polyol network. Several milligrams of dried MPs were analyzed by attenuated total reflection Fourier transform infrared (ATR-FTIR) spectroscopy using a PerkinElmer Spectrum One instrument equipped with a universal ATR assembly. The ester stretch $\left(\approx 1730 \mathrm{~cm}^{-1}\right)$ and the loss of the acrylate $\mathrm{C}=\mathrm{C}$ stretch $\left(1675-1600 \mathrm{~cm}^{-1}\right)$ were used to confirm presence of the covalent crosslinked network ${ }^{58}$

Differential interference contrast microscopy: to visualize and quantify the size of formulated MPs a $1 \mathrm{mg} / \mathrm{ml}$ solution of dispersed MPs was placed on a glass slide, coverslipped and imaged on a Zeiss Axioplan photomicroscope using a $\times 63$ oil objective. Quantification of MPs size was performed on images taken from several separately prepared slides using NIH Image J (1.51) software.

Immunohistochemistry. After terminal anesthesia by barbiturate overdose mice were perfused transcardially with heparinized saline and $4 \%$ paraformaldehyde. Brains were immediately dissected after perfusion and post-fixed in $4 \%$ paraformaldehyde for $6 \mathrm{~h}$. Brains were cryoprotected in 30\% sucrose in Tris-buffered saline $(\mathrm{pH}=7.4)$ (TBS) for at least 3 days with the sucrose solution replaced once after 2 days. Coronal brain sections ( $40 \mu \mathrm{m}$ thick) were cut using a Leica CM3050 cryostat. Brain sections were stored transiently in TBS buffer at $4^{\circ} \mathrm{C}$ or in antifreeze solution of $50 \%$ glycerol $/ 30 \%$ Sucrose in PBS at $-20^{\circ} \mathrm{C}$ for long-term storage. Brain sections were processed for immunofluorescence using a free floating staining protocol involving a $1 \mathrm{~N}$ Hydrochloric acid incubation for $10 \mathrm{~min}$ for antigen retrieval, three washes with TBS buffer, a one hour incubation with 5\% donkey serum in TBS $/ 0.5 \%$ triton $\mathrm{X}-100$ solution to block and permeabilize tissue, then an overnight incubation in primary antibody solution ${ }^{4,5}$. The primary antibodies used in this study were: rabbit anti-GFAP (1:1000; Cat\#Z-0334, Dako, Santa Clara, CA); rat anti-GFAP (1:1000, Cat\#13-0300, Clone-2.2B10, Thermofisher, Grand Island, NY); rabbit anti-NeuN (1:1000, Cat\#Ab177487, Clone-EPR12763, Abcam, Cambridge, MA); guinea pig anti-NeuN (1:1000, Cat\#266-004, Synaptic Systems, Goettingen, Germany); goat anti-CD13 (1:200, Cat\#AF2335, R\&D systems, Minneapolis, MN); rabbit anti-Laminin 1 (1:100, Cat\#L-9393, Sigma, St. Louis, MO); rabbit anti-Fibronectin (1:500, Cat\#AB2033, Millipore, Burlington, MA); rabbit anti-Collagen-1a1 (1:300, Cat\#NB600-408. Novus Biologicals, Littleton, CO); rabbit anti-RFP (1:1000, Cat\#600-401-379, Rockland, Limerick, PA); goat anti-Albumin (1:300, Cat\#NB600-41532, Novus Biologicals, Littleton, CO); rat anti-PECAM-1 (1:200, Cat\#550274, clone-MEC 13.3 BD Biosciences, San Jose, CA); rat anti-Galectin-3 (1:200, Cat\#14-5301-82, Clone-M3/38, InvitrogenThermofisher Scientific, Grand Island, NY); rat anti-CD68 (1:1000, Cat\# MCA1957, CLone-FA-11, AbDserotec-BioRad, Hercules, CA); rat anti-CD45 (1:100, Cat\#553076, Clone-30-F11, BD Biosciences, San Jose, CA); rabbit anti-Iba-1 (1:800, Cat\#019-19741, Wako, Osaka, Japan); guinea pig anti-Iba-1 (1:800,
Cat\#234-004, Synaptic systems, Goettingen, Germany); Rabbit anti-P2Y12R (1:500 Cat\#AS-55043A, Anaspec, Fremont, CA); rabbit anti-mouse IgG (1:1000, Cat\#97042, Abcam, Cambridge, MA); rat anti-Ly6B2 (1:200, Cat\#MCA771GT, Clone-7/4, BioRad, Hercules, CA); Goat anti-PDGFR- $\beta$ (1:200, Cat\#AF1042, R\&D systems, Minneapolis, MN); and rabbit anti-Olig2 (1:200, Cat\#AB9610, Millipore, Burlington, MA). All secondary antibodies used in this study were purchased from Jackson ImmunoResearch (West Grove, PA). Primary antibodies without a designated clone are polyclonal. All primary antibodies used have been previously validated by the manufacturer and confirmed by us for use on mouse paraformaldehyde fixed, frozen cut tissue (validated mouse reactivity) and for use in fluorescent IHC applications. After overnight primary antibody incubation, tissue sections were washed three times with TBS followed by incubation with secondary antibodies in a solution containing 5\% donkey serum for $2 \mathrm{~h}$. All secondary antibodies used in this study were purchased from Jackson ImmunoResearch (West Grove, PA). All secondary antibodies were affinity purified whole $\operatorname{IgG}(\mathrm{H}+\mathrm{L})$ antibodies with donkey host and target species dictated by the specific primary antibody used. All secondary antibodies were stored in $50 \%$ glycerol solution and diluted at a concentration of 1:250 in 5\% normal donkey serum in TBS when incubated with brain histological sections. BDA was visualized with streptavidin HRP plus Tyr-Cy3 (PerkinElmer) ${ }^{4}$. After removal of secondary antibody solution, tissue sections were washed with TBS and nuclei were stained with 4',6'-diamidino2-phenylindole dihydrochloride (DAPI; $2 \mathrm{ng} / \mathrm{ml}$; Molecular Probes). Sections were coverslipped using ProLong Gold anti-fade reagent (InVitrogen, Grand Island, $\mathrm{NY}$ ). Sections were examined and photographed using epifluorescence microscopy, deconvolution fluorescence microscopy and scanning confocal laser microscopy (Zeiss, Oberkochen, Germany). Tiled scans of individual whole sections were prepared using a $\times 20$ objective and the scanning function of a Leica Aperio Versa 200 Microscope (Leica, Wetzlar, Germany) available in the UCLA Translational Pathology Core Laboratory.

Quantification of IHC. Immunohistochemical staining intensity quantification was performed on whole brain images derived from the slide scanner or tiled images prepared on the epifluorescence microscope. All images used for each comparable analysis were taken at a standardized exposure time and used the raw/uncorrected intensity setting. Quantification of antibody staining intensity for the individual hydrogels was performed using NIH Image J (1.51) software and the Radial Profile Angle plugin. The procedure for determining the hydrogel radius and the nonneural and neural compartments is outlined graphically in Supplementary Fig. 2. In brief, a radial profile field of $900 \mu \mathrm{m}$ ( $\sim 846$ pixels) was applied to each hydrogel (this standardized radial profile field was determined as the average field that included all hydrogels and was confined within the $\mathrm{CP}$ region of the brain section (i.e., between the ventricle and corpus callosum)). The radial profile analysis determines the average pixel intensity value across the circumference of a circle at each radial pixel distance. The Hydrogel radius/start of tissue location was determined from the DAPI profile and specifically where the numerical first derivative $(\Delta I n t e n s i t y / \Delta r)$ of the DAPI profile crossed a threshold of +0.2 . The non-neural/ neural tissue boundary was defined as the maximum of the GFAP intensity which was determined where $(\Delta$ Intensity/ $\Delta r)$ equaled zero. All numerical first derivative calculations were performed using Prism 8 (GraphPad Software Inc, San Diego, CA). Total values for CD13, GFAP, Ly6B2, Col1a1, Gal-3, Albumin, IgG, Iba-1, BDA stainings were determined by taking the integral (area under the curve) of the radial intensity profile using Prism 8 software. Albumin and IgG intensities and total values were normalized to the contralateral hemisphere of each animal.

For BDA and NGF delivery quantification only slide scanned images were used. Medial and lateral hem-circular radial analysis was performed in addition to the standard radial profile analysis described above to quantify BDA dispersion throughout whole brain sections. Quantification of the co-staining of BDA with specific immunohistochemical stains such as NeuN, CD13, CD68, Iba-1, IgG, and albumin was performed using the RG2B colocalization plugin in NIH Image J (1.51) software. Number of BDA and NeuN-positive neurons was determined by counting the number of $\mathrm{BDA} / \mathrm{NeuN}$ colocalized staining puncta using the analyze particles function in NIH Image J (1.51) software. Bioactive NGF delivery was assessed by characterizing the size (area) of choline acetyltransferase (ChAT) and NeuN-positive cholinergic neurons also using the analyze particles function in NIH Image J (1.51) software. Orthogonal (3D) images were prepared using Imaris 9.2 (Bitplane).

\section{Statistics, power calculations, group sizes, and reproducibility. Graph gen-} eration and statistical evaluations of repeated measures were conducted by one-way or two-way analysis of variance (ANOVA) with post hoc independent pair wise analysis as per Bonferroni, Tukey, or by Student's $t$-tests (two-sided) where appropriate using Prism 8 (GraphPad Software Inc, San Diego, CA) and Microsoft Excel (Microsoft Office 365 ProPlus). PCA was performed using XLStat (Addinsoft Inc, Long Island City, NY). For one-way and two-way ANOVA statistical evaluations, $P$ values, $F$ values, and degrees of freedom are reported in the manuscript and within the source data files. Similarly, for Student's two-tailed $t$ test, the $t$ value and degrees of freedom are reported. Power calculations were performed using G*Power Software V 3.1.9.2. For immunohistochemical quantification analysis, group sizes were calculated to provide at least $80 \%$ power when using the following parameters: probability of type I error (alpha) $=0.05$, a conservative effect size of 
0.25, 3-10 treatment groups with multiple measurements obtained per replicate. All graphs show mean values plus or minus standard error of the means (s.e.m.) as well as individual values as dot plots. All bar graphs are superimposed with dot plots where each dot represents the value for one animal to show the distribution of data and the number $(n)$ of animals per group. In all images the specific number of mice used per group is specified in the figure legend. Files of all individual values and statistical analysis are provided as source data. Injections of hydrogel formulations were repeated independently at least three times in different cohorts of mice across a 3-year period and were reproduced with similar results. All data derived from independent replications has been included in the data presented.

Reporting summary. Further information on research design is available in the Nature Research Reporting Summary linked to this article.

\section{Data availability}

All data generated for this study are included in the main and supplementary figures. Other data that support the findings of this study are available on reasonable request from the corresponding author. Source data are provided with this paper.

Received: 30 September 2019; Accepted: 22 October 2020;

Published online: 04 December 2020

\section{References}

1. Orive, G., Anitua, E., Pedraz, J. L. \& Emerich, D. F. Biomaterials for promoting brain protection, repair and regeneration. Nat. Rev. Neurosci. 10, 682 (2009).

2. Zhong, Y. \& Bellamkonda, R. V. Biomaterials for the central nervous system. J. R. Soc. Interface 5, 957-975 (2008).

3. Obidin, N., Tasnim, F. \& Dagdeviren, C. The future of neuroimplantable devices: a materials science and regulatory perspective. Adv. Mater. 32, 1901482.

4. Anderson, M. A. et al. Required growth facilitators propel axon regeneration across complete spinal cord injury. Nature 561, 396-400 (2018).

5. Anderson, M. A. et al. Astrocyte scar formation aids central nervous system axon regeneration. Nature 532, 195 (2016).

6. O'Shea, T. M. et al. In Smart Materials for Tissue Engineering: Applications 529-557 (The Royal Society of Chemistry, 2017).

7. Mitrousis, N., Fokina, A. \& Shoichet, M. S. Biomaterials for cell transplantation. Nat. Rev. Mater. 3, 441-456 (2018).

8. Wollenberg, A. L. et al. Injectable polypeptide hydrogels via methionine modification for neural stem cell delivery. Biomaterials 178, 527-545 (2018).

9. Slaughter, B. V., Khurshid, S. S., Fisher, O. Z., Khademhosseini, A. \& Peppas, N. A. Hydrogels in regenerative medicine. Adv. Mater. 21, 3307-3329 (2009).

10. Lacour, S. P., Courtine, G. \& Guck, J. Materials and technologies for soft implantable neuroprostheses. Nat. Rev. Mater. 1, 16063 (2016).

11. Kozai, T. D. Y., Jaquins-Gerstl, A. S., Vazquez, A. L., Michael, A. C. \& Cui, X. T. Brain tissue responses to neural implants impact signal sensitivity and intervention strategies. ACS Chem. Neurosci. 6, 48-67 (2015).

12. Green, R. A., Lovell, N. H., Wallace, G. G. \& Poole-Warren, L. A. Conducting polymers for neural interfaces: challenges in developing an effective long-term implant. Biomaterials 29, 3393-3399 (2008).

13. Elliott Donaghue, I., Tam, R., Sefton, M. V. \& Shoichet, M. S. Cell and biomolecule delivery for tissue repair and regeneration in the central nervous system. J. Control. Release 190, 219-227 (2014).

14. Kearney, C. J. \& Mooney, D. J. Macroscale delivery systems for molecular and cellular payloads. Nat. Mater. 12, 1004 (2013).

15. Loebel, C., Rodell, C. B., Chen, M. H. \& Burdick, J. A. Shear-thinning and selfhealing hydrogels as injectable therapeutics and for 3D-printing. Nat. Protoc. 12, 1521 (2017).

16. Wang, L. L. et al. Sustained miRNA delivery from an injectable hydrogel promotes cardiomyocyte proliferation and functional regeneration after ischaemic injury. Nat. Biomed. Eng. 1, 983-992 (2017).

17. Zhang, L. et al. Zwitterionic hydrogels implanted in mice resist the foreignbody reaction. Nat. Biotechnol. 31, 553 (2013).

18. Appel, E. A. et al. Self-assembled hydrogels utilizing polymer-nanoparticle interactions. Nat. Commun. 6, 6295 (2015)

19. Burda, J. E. \& Sofroniew, M. V. Reactive gliosis and the multicellular response to CNS damage and disease. Neuron 81, 229-248 (2014)

20. Bellver-Landete, V. et al. Microglia are an essential component of the neuroprotective scar that forms after spinal cord injury. Nat. Commun. 10, 518 (2019).

21. Brennan, F. H. et al. Complement receptor C3aR1 controls neutrophil mobilization following spinal cord injury through physiological antagonism of CXCR2. JCI Insight. 4, e98254 (2019).
22. O’Shea, T. M., Burda, J. E. \& Sofroniew, M. V. Cell biology of spinal cord injury and repair. J. Clin. Invest. 127, 3259-3270 (2017)

23. Salatino, J. W., Ludwig, K. A., Kozai, T. D. Y. \& Purcell, E. K. Glial responses to implanted electrodes in the brain. Nat. Biomed. Eng. 1, 862-877 (2017)

24. Nowak, A. P. et al. Rapidly recovering hydrogel scaffolds from self-assembling diblock copolypeptide amphiphiles. Nature 417, 424-428 (2002).

25. Yang, C.-Y. et al. Biocompatibility of amphiphilic diblock copolypeptide hydrogels in the central nervous system. Biomaterials 30, 2881-2898 (2009).

26. Webber, M. J., Appel, E. A., Meijer, E. W. \& Langer, R. Supramolecular biomaterials. Nat. Mater. 15, 13 (2015).

27. Nunez, S. et al. A versatile murine model of subcortical white matter stroke for the study of axonal degeneration and white matter neurobiology. J. Vis. Exp. 109, 53404 (2016).

28. Shipp, M. A. \& Look, A. T. Hematopoietic differentiation antigens that are membrane-associated enzymes: cutting is the key! Blood 82, 1052-1070 (1993).

29. Armulik, A. et al. Pericytes regulate the blood-brain barrier. Nature 468, 557 (2010).

30. Bush, T. G. et al. Leukocyte infiltration, neuronal degeneration, and neurite outgrowth after ablation of scar-forming, reactive astrocytes in adult transgenic mice. Neuron 23, 297-308 (1999).

31. Tate, M. C., Shear, D. A., Hoffman, S. W., Stein, D. G. \& LaPlaca, M. C. Biocompatibility of methylcellulose-based constructs designed for intracerebral gelation following experimental traumatic brain injury. Biomaterials 22, 1113-1123 (2001).

32. Gupta, D., Tator, C. H. \& Shoichet, M. S. Fast-gelling injectable blend of hyaluronan and methylcellulose for intrathecal, localized delivery to the injured spinal cord. Biomaterials 27, 2370-2379 (2006).

33. Crompton, K. E. et al. Inflammatory response on injection of chitosan/GP to the brain. J. Mater. Sci. 17, 633-639 (2006)

34. Song, B. et al. Sustained local delivery of bioactive nerve growth factor in the central nervous system via tunable diblock copolypeptide hydrogel depots. Biomaterials 33, 9105-9116 (2012).

35. Jeong, H.-K. et al. Inflammatory responses are not sufficient to cause delayed neuronal death in ATP-induced acute brain injury. PLOS ONE 5, e13756 (2010).

36. Sasaki, Y. et al. Selective expression of Gi/o-coupled ATP receptor P2Y12 in microglia in rat brain. Glia 44, 242-250 (2003).

37. Haynes, S. E. et al. The P2Y12 receptor regulates microglial activation by extracellular nucleotides. Nat. Neurosci. 9, 1512-1519 (2006).

38. Kendall, R. T. \& Feghali-Bostwick, C. A. Fibroblasts in fibrosis: novel roles and mediators. Front. Pharmacol. 5, 123 (2014).

39. Fernandez-Klett, F. et al. Early loss of pericytes and perivascular stromal cellinduced scar formation after stroke. J. Cereb. Blood Flow Metab. 33, 428-439 (2013).

40. Aldrich, A. \& Kielian, T. Central nervous system fibrosis is associated with fibrocyte-like infiltrates. Am. J. Pathol. 179, 2952-2962 (2011)

41. Henderson, N. C. et al. Galectin-3 regulates myofibroblast activation and hepatic fibrosis. Proc. Natl. Acad. Sci. USA 103, 5060-5065 (2006)

42. Lalancette-Hébert, M. et al. Galectin-3 is required for resident microglia activation and proliferation in response to ischemic injury. J. Neurosci. 32, 10383-10395 (2012)

43. Fernández-Klett, F. \& Priller, J. The fibrotic scar in neurological disorders. Brain Pathol. 24, 404-413 (2014).

44. Li, L.-c, Li, J. \& Gao, J. Functions of galectin-3 and its role in fibrotic diseases J. Pharmacol. Exp. Ther. 351, 336-343 (2014).

45. Yan, Y.-P., Lang, B. T., Vemuganti, R. \& Dempsey, R. J. Galectin-3 mediates post-ischemic tissue remodeling. Brain Res. 1288, 116-124 (2009).

46. Sirko, S. et al. Astrocyte reactivity after brain injury: the role of galectins 1 and 3. Glia 63, 2340-2361 (2015)

47. Rakers, C. et al. Stroke target identification guided by astrocyte transcriptome analysis. Glia 67, 619-633 (2019).

48. Hortobagyi, T. et al. Traumatic axonal damage in the brain can be detected using beta-APP immunohistochemistry within $35 \mathrm{~min}$ after head injury to human adults. Neuropathol. Appl. Neurobiol. 33, 226-237 (2007).

49. O'Brien, R. J. \& Wong, P. C. Amyloid precursor protein processing and Alzheimer's disease. Annu. Rev. Neurosci. 34, 185-204 (2011).

50. Sokrab, T.-E. O., Johansson, B. B., Kalimo, H. \& Olsson, Y. A transient hypertensive opening of the blood-brain barrier can lead to brain damage. Acta Neuropathol. 75, 557-565 (1988).

51. Sherriff, F. E., Bridges, L. R. \& Sivaloganathan, S. Early detection of axonal injury after human head trauma using immunocytochemistry for betaamyloid precursor protein. Acta Neuropathol. 87, 55-62 (1994).

52. Kumar, D. K. V. et al. Amyloid- $\beta$ peptide protects against microbial infection in mouse and worm models of Alzheimer's disease. Sci. Transl. Med. 8 340ra372-340ra372 (2016).

53. Wu, Y. et al. Microglia and amyloid precursor protein coordinate control of transient Candida cerebritis with memory deficits. Nat. Commun. 10, 58 (2019). 
54. Zhu, X. et al. Age-dependent fate and lineage restriction of single NG2 cells. Development 138, 745-753 (2011).

55. Sofroniew, M. V. Astrocyte barriers to neurotoxic inflammation. Nat. Rev. Neurosci. 16, 249 (2015).

56. Baumann, M. D. et al. An injectable drug delivery platform for sustained combination therapy. J. Control. Release 138, 205-213 (2009).

57. Mura, S., Nicolas, J. \& Couvreur, P. Stimuli-responsive nanocarriers for drug delivery. Nat. Mater. 12, 991 (2013).

58. O'Shea, T. M., Aimetti, A. A., Kim, E., Yesilyurt, V. \& Langer, R. Synthesis and characterization of a library of in-situ curing, nonswelling ethoxylated polyol thiol-ene hydrogels for tailorable macromolecule delivery. Adv. Mater. 27, 65-72 (2015)

59. Murthy, N. et al. A macromolecular delivery vehicle for protein-based vaccines: acid-degradable protein-loaded microgels. Proc. Natl. Acad. Sci. 100, 4995-5000 (2003).

60. Tibbitt, M. W., Han, B. W., Kloxin, A. M. \& Anseth, K. S. Student award for outstanding research winner in the Ph.D. category for the 9th World Biomaterials Congress, Chengdu, China, June 1-5, 2012. J. Biomed. Mater. Res. Part A 100A, 1647-1654 (2012).

61. Champion, J. A., Walker, A. \& Mitragotri, S. Role of particle size in phagocytosis of polymeric microspheres. Pharm. Res. 25, 1815-1821 (2008).

62. Wolak, D. J. \& Thorne, R. G. Diffusion of macromolecules in the brain: implications for drug delivery. Mol. Pharm. 10, 1492-1504 (2013).

63. Armstrong, J. K., Wenby, R. B., Meiselman, H. J. \& Fisher, T. C. The hydrodynamic radii of macromolecules and their effect on red blood cell aggregation. Biophys. J. 87, 4259-4270 (2004).

64. Smith, A. J., Yao, X., Dix, J. A., Jin, B.-J. \& Verkman, A. S. Test of the 'glymphatic' hypothesis demonstrates diffusive and aquaporin-4-independent solute transport in rodent brain parenchyma. Elife 6, e27679 (2017).

65. Aggarwal, P., Hall, J. B., McLeland, C. B., Dobrovolskaia, M. A. \& McNeil, S. E. Nanoparticle interaction with plasma proteins as it relates to particle biodistribution, biocompatibility and therapeutic efficacy. Adv. drug Deliv. Rev. 61, 428-437 (2009).

66. Sofroniew, M. V. et al. Atrophy but not death of adult septal cholinergic neurons after ablation of target capacity to produce mRNAs for NGF, BDNF, and NT3. J. Neurosci. 13, 5263-5276 (1993).

67. Sofroniew, M. V., Galletly, N. P., Isacson, O. \& Svendsen, C. N. Survival of adult basal forebrain cholinergic neurons after loss of target neurons. Science 247, 338-342 (1990).

68. Yu, X., Nagai, J. \& Khakh, B. S. Improved tools to study astrocytes. Nat. Rev. Neurosci. 21, 121-138 (2020).

69. Dana, $\mathrm{H}$. et al. High-performance calcium sensors for imaging activity in neuronal populations and microcompartments. Nat. Methods 16, 649-657 (2019).

70. Eles, J. R., Vazquez, A. L., Kozai, T. D. Y. \& Cui, X. T. Meningeal inflammatory response and fibrous tissue remodeling around intracortical implants: An in vivo two-photon imaging study. Biomaterials 195, 111-123 (2019).

71. Spencer, K. C. et al. Characterization of mechanically matched hydrogel coatings to improve the biocompatibility of neural implants. Sci. Rep. 7, 1952 (2017).
72. Liu, Y. et al. Soft and elastic hydrogel-based microelectronics for localized lowvoltage neuromodulation. Nat. Biomed. Eng. 3, 58-68 (2019).

\section{Acknowledgements}

This work was supported by US National Institutes of Health (NS084030 to M.V.S.); Dr. Miriam and Sheldon G. Adelson Medical Foundation (M.V.S. and T.J.D); Craig H Neilsen Foundation (381357 to T.M.O.); Paralyzed Veterans Foundation of America (RF3170 to T.M.O.); American Australian Association (T.M.O.), Wings for Life Spinal Cord Research Foundation (M.V.S. and T.M.O.); and Microscopy Core Resource of UCLA Broad Stem Cell Research Center.

\section{Author contributions}

T.M.O., T.J.D., and M.V.S. designed experiments; T.M.O., A.L.W., J.H.K., and Y.A. conducted experiments; T.M.O., A.L.W, T.J.D., and M.V.S. analyzed data. T.M.O., T.J.D., and M.V.S. prepared the manuscript.

\section{Competing interests}

The authors declare no competing interests.

\section{Additional information}

Supplementary information is available for this paper at https://doi.org/10.1038/s41467 020-19906-3.

Correspondence and requests for materials should be addressed to M.V.S.

Peer review information Nature Communications thanks Janak Gaire and other, anonymous, reviewers for their contributions to the peer review of this work.

Reprints and permission information is available at http://www.nature.com/reprints

Publisher's note Springer Nature remains neutral with regard to jurisdictional claims in published maps and institutional affiliations.

Open Access This article is licensed under a Creative Commons Attribution 4.0 International License, which permits use, sharing, adaptation, distribution and reproduction in any medium or format, as long as you give appropriate credit to the original author(s) and the source, provide a link to the Creative Commons license, and indicate if changes were made. The images or other third party material in this article are included in the article's Creative Commons license, unless indicated otherwise in a credit line to the material. If material is not included in the article's Creative Commons license and your intended use is not permitted by statutory regulation or exceeds the permitted use, you will need to obtain permission directly from the copyright holder. To view a copy of this license, visit http://creativecommons.org/ licenses/by/4.0/.

(c) The Author(s) 2020 